\title{
Reaktionen und Adaptationen wechselwarmer Tiere nach einer Anderung der Anpassungstemperatur und der zeitliche Verlauf
}

\author{
Herbert Precht, Thies Basedow, Reiner Bereck, \\ Frauke Lange, Wolfgang Thiede und Lotte Wilke \\ Zoologisches Institut der Universität Kiel, Lehrstubl für vergleichende \\ Physiologie und Tierpsycbologie
}

\begin{abstract}
ABST'RACT: Reactions and adaptations of poikilotherm animals after a change of adaptation temperature and the time course. The reactions and adaptations after changes in adaptation temperature are recorded, and the process of their development (time course) is described. In the fish $I d u s$ idus the frequency of operculum movements decreases continuously over a long period if the temperature to which it has been adapted is suddenly lowered. In females of Xiphophorus belleri the process leading to adaptation under new conditions is followed by watching the operculum movements at several experimental temperatures. This process is itself dependent on the experimental temperature and has different results for the various ranges of experimental temperatures. The values of heat resistance in $I d u s$ idus are dependent on the speed of the raise in temperature. The phenomenon of "hardening" (in the sense of AlEXANDROV 1964) could not be separated with certainty from a resistance adaptation in the fishes Idus idus, Anguilla vulgaris, Xiphophorus belleri and the ciliate Zoothamnium biketes. After changing the adaptation temperature, the rapid changes of the cold resistance in the ciliar epithelium on the antennal ends of the snail Planorbis comeus (also on isolated antennae) were measured. In addition, changes in the cold resistance of Xiphophorus belleri females in regard to the standstill of the operculum as well as changes in the index of heat lethality were measured.
\end{abstract}

\section{EINLEITUNG}

Bei wechselwarmen Tieren unterscheiden sich oftmals die unter gleichen Versuchsbedingungen gemessenen physiologischen Leistungswerte von Rassen oder verwandten Arten aus geographisch weit entfernten Gebieten. Dafür können genetische Anpassungen verantwortlich sein, aber auch die hier allein interessierenden $n i c h t-$ genetischen Adaptationen. Bei sich rasch vermehrenden Organismen (z. B. Mikroorganismen) müssen beide Typen der Adaptation in Versuchen sorgsam getrennt werden, da zum Beispiel die Selektion bestimmter genetischer Formen eine nichtgenetische Anpassung vortäuschen kann.

Betrachten wir zunächst die Faktoren, durch welche die Ansprechbarkeit der Lebensprozesse auf die Versuchstemperatur im normalen Temperaturbereich oder die 
Resistenz der wechselwarmen Tiere beziehungsweise der untersuchten Organfunktionen oder Zellstoffwechselprozesse beeinflußt werden kann. Es können Anpassungen an die Jahreszeiten vorliegen, wenn diese größere Temperaturunterschiede aufweisen. Über längere Zeit einwirkende Temperaturen haben oft Anpassungen zur Folge, die noch eingehend erörtert werden sollen. Die Leistungswerte im normalen Temperaturbereich und die Resistenzwerte gegenüber extremen Temperaturen können sich aber auch unabhängig von der Adaptationstemperatur (AT) im Laufe des Jahres ändern. Vielfach hat die Tageslänge als Zeitgeber eine große Bedeutung, da sie die Jahreszeit eindeutiger anzeigt als die Temperatur (über den Einfluß der Tageslänge im normalen Temperaturbereich vgl. RoberTs 1961, 1964, Evans et al. 1962, WHITFORD \& Hutchison 1965, Kasbomm 1967, im extremen Temperaturbereich vgl. Hoar \& Robertson 1959, Hutchison 1961, Vogel 1966). Lassen sich keine exogenen Zeitgeber finden, so können jahreszeitliche Anpassungen unter Umständen auf einer endogenen Jahresthythmik beruhen (PRECHT 1964a). Der Stoffwechsel von Arten, die im Winter aktiv sind, ist unter gleichen Versuchsbedingungen durch diese Anpassungen im Winter oft höher als im Sommer. Bei Arten mit spezieller Ruhephase ist er dagegen im Winter im allgemeinen herabgesetzt. Die Hitzeresistenz ist zumeist während der warmen Jahreszeit groß, die Kältewiderstandsfähigkeit während der kalten.

Viele wechselwarme Tiere sind aber auch zur gleichen Jahreszeit erheblichen Temperaturschwankungen ausgesetzt. Hier spielt häufig die Adaptation an eine bestimmte Vorbehandlungstemperatur (AT) eine wichtige Rolle, die man von der Versuchstemperatur (VT) unterscheiden muß. Auf eine Präzisierung der Ausdrücke Reaktion, Regulation und Adaptation ( $=$ Akklimatisation) und das deutsche Wort Anpassung, welches teils nur für Adaptation gebraucht wird, in bestimmten Fällen aber auch für Regulation, wird an einer anderen Stelle eingegangen, ebenfalls auf das Problem des Nutzens im Sinne eines Selektionsvorteils, der mit einer Adaptation verbunden sein kann (Precht \& Lindner 1966). Die vorliegende Abhandlung befaßt sich mit Reaktionen und Adaptationen.

Bei Anpassung an veränderte Temperaturen unterscheidet man zweckmäBigerweise zwischen Lebensprozessen, die während des Versuchs im wesentlichen unverändert bleiben und anderen sich ändernden Reaktionssystemen. Für die Beurteilung der hierzu gehörenden Wachstums- und Entwicklungsprozesse dient die Zeit der Anderung direkt als Maß. Bei der Untersuchung der Temperaturabhängigkeit der Entwicklung eines Insekts liegt dieses zum Beispiel am Anfang als Ei, zum Schluß als Larve oder Imago vor. Derartige Versuche führt man gewöhnlich bei verschiedenen konstant bleibenden Temperaturen durch; es handelt sich somit um voll adaptierte Tiere. Man hat früher nicht bedacht, daß sich diese Prozesse bei relativ raschen Temperaturänderungen anders verhalten können.

Den sich ändernden Reaktionssystemen stehen die sich nicht ändernden gegenüber. Bei diesen Systemen (z. B. den Betriebsstoffwechselprozessen) hatte man gerade umgekehrt die Versuchstemperatur relativ rasch verändert und den Einfluß einer langfristig einwirkenden Vorbehandlungstemperatur (AT) übersehen, durch den sogar der Kohlenhydratabbauweg verändert werden kann (EKBERG 1958, HochachKa \& HAYES 1962, Irlina 1964, Poljansky \& Sukhanova 1964).

In dieser Abhandlung soll vor allem auf den zeitlichen Verlauf der Anderung der 
Lebensprozesse nach einem Wechsel der AT eingegangen werden. In den Vordergrund stellen wir absichtlich die von uns eingehender bearbeiteten stoffwechselphysiologischen Probleme bei sich nicht ändernden Reaktionssystemen, wobei nur die Folgen einer Anderung der AT berücksichtigt werden sollen, nicht jedod die früher zumeist allein untersuchte Abhängigkeit der Lebensprozesse von der VT. Neuere Versuche werden als Beispiele mitgeteilt. Tabelle 1 gibt eine Ubersicht über die zu besprechenden Reaktionen und Anpassungen. Morphologische Veränderungen sind in ihr nicht berücksichtigt worden, ebensowenig Probleme, die mit dem Temperatursinn der Tiere zusammenhängen (vg1. PRECHT et al. 1955, p. $144 \mathrm{ff}$.). Auf das Zusammenwirken mehrerer Faktoren, das von McLeese $(1956)$, KInNe $(1963,1964)$ und anderen untersucht worden ist, wird nicht eingegangen. Auch die besonderen Verhältnisse bei Bienen (vgl. Esch 1960, Roth 1964, Heusner \& STussi 1964) und erste Ansätze zur Regulierung der Körpertemperatur bei wechselwarmen Wirbeltieren sind ausgeklammert worden.

In Tabelle 1 sind vorübergehende und bleibende Phänomene unterschieden worden; das von den Botanikern eingehend untersuchte, aber für Tiere noch ungenügend bekannte "hardening" haben wir (vorerst) in die erste Kategorie eingereiht. Die Leistungs- und Resistenzadaptation sind bleibende Anpassungen an eine bestimmte AT; sie kann man bei den Metazoen bis auf die Zellebene verfolgen. Bei der Leistungsadaptation kann die Aktivität und auch die Quantität vieler Fermente

Tabelle 1

Wirkungen einer Änderung der Adaptationstemperatu:

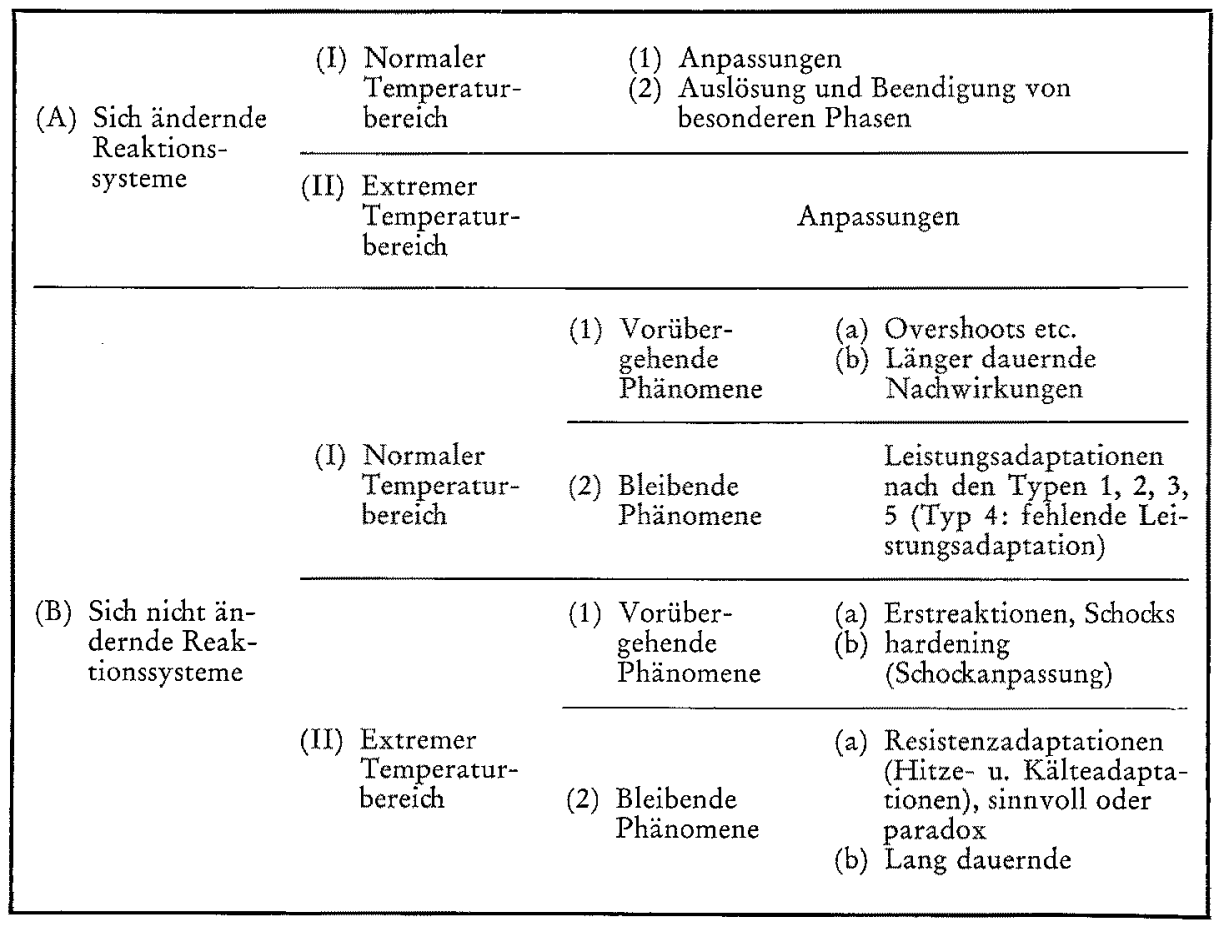


beeinflußt sein, ebenfalls die Zahl der Mitochondrien (BoycotT et al. 1961, JANKOWSKY \& KORN 1965). Eine Komplikation tritt dadurch auf, daß die verschiedenen Gewebe eines Tieres auf eine Anderung der AT unterschiedlich ansprechen können. Schon daraus ergibt sich, daß beispielsweise der Sauerstoffverbrauch eines intakten Tieres nicht die gleichen Anpassungserscheinungen zu zeigen braucht wie der eines isoliert untersuchten Gewebes (PRECHT 1964b). Da anscheinend reine Eiweiße eine gewisse Resistenzadaptation zeigen können, erweist sich sogar eine Untersuchung der einzelnen Verbindungen als notwendig (vgl. CHRISTOPHERSEN 1963).

Es bleibt stets zu untersuchen, ob die AT direkt die Gewebe beeinflußt oder auf dem Umwege über höhere Systeme (wie das ZNS oder Hormone). Diese übergeordneten Faktoren können in Form von Direkt-oder Nacheffekten auf das Gewebe einwirken. Wenn beispielsweise ein Hormon über genabhängige Prozesse die Proteinsynthese und damit die Fermentquantität ändert, so liegen Nacheffekte vor, die man auch beim isolierten Gewebe messen kann. Direkteffelate durch die übergeordneten Faktoren hinterlassen keine Nachwirkungen und können deshalb nach der Isolierung des Gewebes nidht mehr gefunden werden. Solche Direkteffekte können zum Beispiel vom ZNS ausgehen (vgl. BENTHE 1954), aber auch von der Blutflüssigkeit (SAROJA \& RAo 1965, JANkowsky 1964, Precht 1964c, 1965). In all diesen Fällen handelt es sich um bleibende Phänomene.

Vorübergehende Erscheinungen können wie bei den overshoots darauf beruhen, $\mathrm{daß}$ die Einstellung eines neuen steady-state-Zustandes eine gewisse Zeit in Anspruch nimmt. Bei länger dauernden vorübergehenden Phänomenen ist zu prüfen, ob sie sich bei den Metazoen bis auf Zellebene verfolgen lassen.

\title{
SICH đNDERNDE REAKTIONSSYSTEME
}

\author{
Normaler Temperaturbereich
}

\section{Anpassungen}

Wie erwähnt, hat man die Tiere bei der Untersuchung der Temperaturabhängigkeit der Entwicklungsvorgänge zumeist bei mehreren konstanten Temperaturen gehalten. Da man bei derartigen Messungen im allgemeinen normale Temperaturkoeffizienten erhielt, können Anpassungseffekte - wie bei der Leistungsadaptation - keine größere Rolle spielen. Es sind allerdings zumeist Insekten untersucht worden, deren Betriebsstoffwechsel auch oftmals eine Leistungsadaptation vermissen läßt (vgl. LüHMANN \& DreEs 1952, I. PrEcht 1967). Bei Amphibien konnten jedoch von mehreren Autoren Anpassungen nachgewiesen werden (vgl. PRECHT et al. 1955, p. 100). Man hält bei derartigen Versuchen die Entwidklungsstadien bei einer konstanten Temperatur und überführt sie dann in eine andere, wobei sich ein Vergleich mit Kontrollen ergibt, die sich stets bei dieser Temperatur befanden. Grainger (1959) konnte bei seinen Versuchen mit sich entwickelnden Eiern von Rana temporaria allerdings keinen sicheren Nachweis für eine echte Anpassung (after-effect) erbringen, ebensowenig sein Schüler KHAN (1965) für die Entwicklung von Acantbocyclops viridis und Drosopbila 
melanogaster. Hingegen wurde die Länge des adulten Lebens des Copepoden durch die Temperatur beeinflußt, bei der sich die Larven entwickelten. - Nach Kovaljeva \& Selivanova (1963) steigt die Vermehrungsrate von Paramecium caudatum nach Uberführung von $4^{0}$ in $22^{\circ} \mathrm{C}$ zunächst an, um später wieder abzunehmen.

Es wäre interessant, die Entwicklung von solchen Tieren auf diese Probleme hin zu untersuchen, deren Betriebsstoffwechsel eine ausgesprochene Leistungsadaptation aufweist.

Auslösung und Beendigung von besonderen Phasen

Auf diesbezügliche Probleme sei nur hingewiesen. Häufig untersucht wurden die Diapausen von Insekten, für deren Auslösung die Temperatur eine Bedeutung haben kann, viel häufiger aber für deren Beendigung. Optimal sind hierfür bestimmte, relativ niedrige Temperaturen, die oft schon während des Winters die Diapause in eine Quieszens verwandeln (vgl. MüLlER 1966, Tischler 1965 und andere).

Die Faktoren, die eine Diapause auslösen oder beenden, mïssen oftmals in besonderen sensiblen Phasen wirken; der Erfolg zeigt sich dann erst später. Es kann sogar die Temperatur, die auf die Elterntiere einwirkte, entscheidend sein.

\section{Extremer Temperaturbereich}

\section{Anpassungen}

Bei der hier diskutierten Änderung der Reaktionssysteme interessiert nicht die Lebensresistenz der einzelnen Entwicklungsstadien, sondern die Widerstandsfähigkeit der Entwicklungsvorgänge gegenüber extremen Temperaturen. Eine Abgrenzung von den später zu erörternden Resistenzproblemen ist nicht immer einfach, doch werden hier of Synthesen betroffen, bei der Ermittlung der Lebensresistenz jedoch andere Prozesse (Proteindenaturierungen etc.). Die Häutung des 4. Larvenstadiums von Rbodnius zum Beispiel unterbleibt nach Okasha (1964) deshalb bei hohen Temperaturen, weil das Aktivationshormon des Cerebralganglions nicht ausgeschüttet wird durch Blockierung der Proteinsynthese. Bei Mikroorganismen ist die untere Grenztemperatur der Vermehrung oft dadurch festgelegt, daß für die Synthese wichtige Intermediärprodukte in zu geringer Konzentration vorliegen, bedingt durch eine unterschiedliche Temperaturabhängigkeit der einzelnen Prozesse. Durch den Zusatz von Substraten kann man das Vermehrungsminimum verschieben und zwar um so mehr, je kürzer der Stoffwechselweg vom angebotenen Nährstoffzusatz zum benötigten Intermediärprodukt ist (INGRAM 1962, HoFmMANN 1966, unveröffentlichte Dissertation unter Anleitung von Prof. Christophersen). Eine Resistenzadaptation der Vermehrung müßte zu deutlichen Veränderungen führen. Es ist verständlich, daß die Temperaturgrenzen für die Entwicklung der Organismen meist enger sind als die für das Überleben.

Eine weitere Schwierigkeit ergibt sich aus folgendem Problem: Beim Sauerstoffverbrauch der Tiere oder ihrer Gewebe liegt der Umkehrpunkt der Kurven bei relativ 
hohen Versuchstemperaturen (vgl. Precht 1960b, OHLEnbusch \& PRecht 1960). Seine Lage kann sich mit der AT verschieben, was man als eine Resistenzadaptation bezeichnen kann, wenn Temperaturen oberhalb des Umkehrpunktes zum unbiologischen Bereich gehören. Bei anderen Lebensprozessen - und dazu gehören im allgemeinen auch die Entwicklungsvorgänge - liegt der Umkehrpunkt der Kurven bei relativ niedrigen Versuchstemperaturen. Entomologen sprechen sogar von einer optimalen Temperatur, bei der die Entwicklung am raschesten abläuft. Sie liegt im "normalen“ Temperaturbereich und ihre Anderung durch die AT würde man kaum als Resistenzproblem auffassen (vgl. PRecht et al. 1955, p. 89).

Bei Einzellern kann man bei der Untersuchung der Änderung der Systeme nur ihre Vermehrung erfassen. Bei der Hefe Torulopsis kefyr, die sich auch bei Temperaturen oberhalb des Umkehrpunktes der Teilungskurven gut züchten läßt, zeigt dieser keine Abhängigkeit von der AT (Christophersen \& Precht 1950a). Durch Kultur bei $12,5^{\circ} \mathrm{C}$ steigert sich bei dem Ciliaten Tetrabymena pyriformis während einiger $\mathrm{Ge}-$ nerationen einerseits die Kälteresistenz und andererseits die Hitzeempfindlichkeit der Vermehrung; eine Überführung aus normalen Temperaturen in $30,7^{\circ} \mathrm{C}$ hat den entgegengesetzten Effekt (Thormar 1962, vgl. Chrustophersen in Precht et al. 1955, p. 214). Propper (1965) hielt Kulturen von Paramecium caudatum fünf bis sechs Monate bei $4^{\circ}, 20^{\circ}$ und $30^{\circ} \mathrm{C}$, wobei natürlich eine Selektion bestimmter genetischer Typen stattfinden kann, die noch ausgeschlossen werden müßre. In kurzfristigen Temperaturversuchen war das Vermehrungsoptimum der bei $30^{\circ} \mathrm{C}$ gehaltenen Tiere deutlich nach höheren Temperaturen hin verschoben, ebenso die Grenztemperatur der Vermehrung. Bei tiefen Temperaturen vermehrten sich die bei $4^{\circ} \mathrm{C}$ gehaltenen Tiere stärker als die bei $20^{\circ} \mathrm{C}$ gehaltenen Tiere, und diese wiederum teilten sich häufiger als die lange Zeit bei $30^{\circ} \mathrm{C}$ gezüchteten Paramecien.

\title{
SICH NICHT ANDERNDE REAKTIONSSYSTEME
}

\author{
Normaler Temperaturbereich
}

Vorübergehende Phänomene

\section{Overshoots etc.}

Bei einer Temperaturänderung wird der jeweilige Zustand des Fließgleichgewichts geändert, was sich in mehr oder weniger rasch ablaufenden overshoots und undershoots bemerkbar machen kann, die von GRAINGER $(1959,1960)$ und neuerdings von ZERBST $(1964,1966)$ bearbeitet worden sind. Gelegentlich treten auch Oszillationen auf, bevor ein neuer konstanter Wert erreicht ist (Grainger 1960, vgl. Gosh \& Chance 1964).

ZERBST unterscheidet - wie bei der später zu erörternden Leistungsadaptation 5 Typen, die er an einem elektrischen Modell demonstrieren konnte (vgl. auch BEHMANN \& MEIssner 1964). Es handelt sich nach Zerbst um Einschwingprozesse, also Reaktionen, die sich zwanglos aus den Eigenschaften des lebenden Systems ergeben und 
keine übergeordneten Regulationen notwendig machen. ZERBST arbeitete mit isolierten Herzen von Rana esculenta und solchen in situ. Bei einer raschen Temperatursteigerung $\left(10^{\circ} \rightarrow 25^{\circ} \mathrm{C}\right)$ nimmt die Frequenz des Herzschlags in situ zunächst überschießend zu, bis nach $6 \mathrm{~min}$ ein steady-state- Wert erreicht ist; nach einem folgenden Senken der Temperatur auf $10^{\circ} \mathrm{C}$ nimmt die Frequenz zunächst unterschießend $a b$, um nach etwa $90 \mathrm{~min}$ wieder den Ausgangswert zu erreichen. Bei langsamer Temperatursteigerung stellt sich die Frequenz nicht überschießend, sondern graduell auf den neuen Wert ein. Bei Herzen von warmadaptierten Fröschen wurden die steady-state-Werte nach Temperatursprüngen schneller erreicht als bei solchen von kaltadaptierten Tieren.

Kürzlich fand Nopp (1965) für den Sauerstoffverbrauch und besonders deutlich für den Herzschlag von Stylommatophoren Phänomene, die den overshoots gleichen und nur bei sehr raschen Temperatursteigerungen auftraten. Es bleibt zu untersuchen, ob man die gefundene starke Unabhängigkeit von der Temperatur als schnelle Anpassung deuten darf.

Die Unterscheidung der over- und undershoots von komplexeren Phänomenen, die auch zeitlich länger dauern, ist nicht immer einfach.

\title{
Länger dauernde Nacbwirkungen
}

Erscheinungen, die bereits zu den eigentlichen Anpassungen überleiten, beobachtete zum Beispiel WIEser (1965) bei der Assel Porcellio scaber. Nach einer Senkung der AT $\left(20^{\circ} \rightarrow 8,6^{\circ} \mathrm{C}\right)$ wird der Sauerstoffverbrauch von Wintertieren für einige Tage gesteigert, um dann wieder auf den alten Wert abzufallen (VT stets $20^{\circ} \mathrm{C}$ ). Sommertiere zeigten diese Erscheinung nicht. Bei Weibchen von Schwertträgern (Xiphophorus belleri) stieg der Sauerstoffverbrauch am Tag nach einem Wechsel der AT $\left(19^{\circ} \rightarrow 31^{\circ} \mathrm{C}\right)$, um erst später im Sinne einer Kompensation unter den Wert für die bei $19^{\circ} \mathrm{C}$ gehaltenen Tiere zu fallen (VT stets $25^{\circ} \mathrm{C}$, nach PRECHT 1962).

LANGE überführte langfristig an $8^{\circ}$ beziehungsweise $25^{\circ} \mathrm{C}$ angepaßte Nerflinge (Silberorfen, Idus idus L.) stufenweise in die mittlere Temperatur von $16,5^{\circ} \mathrm{C}$ und beließ sie darin. Der Temperaturkoeffizient für die Kiemendeckelbewegungen der Fische betrug nach der Senkung der AT zunächst $2,9^{\circ} \pm 0,18^{\circ} \mathrm{C}$. Der Abfall der Frequenz hielt auch am nächsten Tage an (Abb. 1); der Endwert wird erst langsam erreicht. Bei

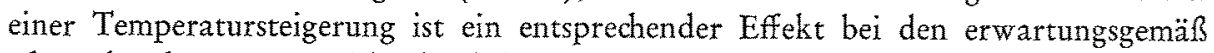
schwankenden Werten nicht deutlich.

\author{
Bleibende Phänomene \\ Leistungsadaptationen nach den Typen 1,2,3 und 5 \\ (Typ $4=$ feblende Leistungsadaptation)
}

Die Leistungsadaptation erfaßt man am besten, wenn man an verschiedene Temperaturen langfristig angepaßte Tiere bei der gleichen VT mißt; noch besser ist die Verwendung mehrerer Versuchstemperaturen. Gewisse Vorsichtsmaßregeln sind bei derarti- 
gen Versuchen zu berücksichtigen (vgl. PRECHT in Prosser 1958). Bei Umadaptationsversuchen, bei denen der zeitliche Verlauf der Anpassung gemessen werden soll, überführt man langfristig angepaßte Tiere in eine neue AT. KINne (1964) unterscheidet bei allen derartigen Versuchen mehrere Phasen (Simultanreaktion, Stabilisierung und neuer stationärer Zustand). Der zeitliche Verlauf der Leistungsadaptation, der meist einige Tage oder eine noch längere Zeit in Anspruch nimmt, ist des öfteren untersucht worden

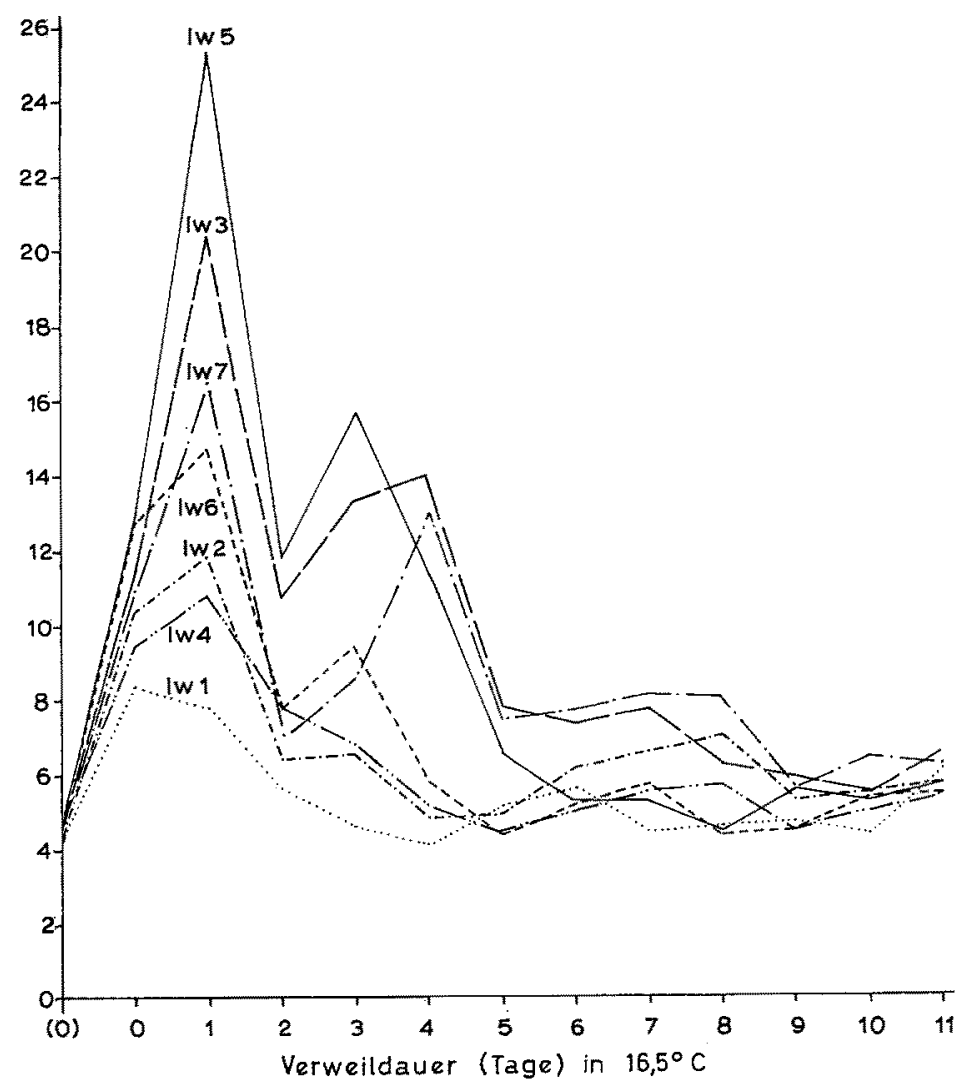

Abb. 1: Frequenz der Kiemendeckelbewegungen von warmadaptierten Silberorfen (Idus idus) nach einer Umadaptation (AT $25^{\circ} \rightarrow 16,5^{\circ} \mathrm{C}$, Leistungsadaptation). Abszisse: Tage in 16,50 $\mathrm{C}$. Bei (O) ist die Frequenz bei VT $25^{\circ}$ angegeben (Messung um 8 Uhr). Dann erfolgte die stufenweise Uberführung in $16,5^{\circ}$ ( $3^{\circ}$ Senkung innerhalb von $2 \mathrm{Std}$.). Die Messung bei 0 erfolgte um 14 Uhr bei $16,5^{\circ} \mathrm{C}$. Ordinate: Dauer von $10 \mathrm{Kiemendeckelbewegungen} \mathrm{in} \mathrm{sec}$

(vgl. Wells 1935, Sumner \& Doudoroff 1938, Stroganov 1940, Freeman 1950, Hutchison 1961). Es handelt sich um eine Anpassung an einen länger dauernden Temperaturwechsel, nicht an die Tagesschwankungen. Bei sich rasch vermehrenden Einzellern kann die Anpassung allerdings relativ schnell beendet sein. Die Änderung der Peroxydase-Aktivität der Hefe Torulopsis kefyr ist bei einer Erhöhung der Zuchttemperatur von $20^{\circ}$ auf $40^{\circ} \mathrm{C}$ in etwa einem halben Tage abgeschlossen; sie dauert bei einer entsprechenden Senkung der AT länger (Christophersen \& Precht 1950, p. 251). 
Die Anpassung selbst ist hier - wie in anderen Fällen - temperaturabhängig. Dies gilt auch für die Resistenzadaptation und wird dort eingehender erörtert (p. 390).

Hier sei noch ein Beispiel für die Leistungsadaptation angeführt. THIEDE hat in teilweise bereits publizierten Untersuchungen die zentralnervös gesteuerten Kiemendeckelbewegungen von $q 9$ des Schwertträgers (Xiphopborus helleri) als Maß für

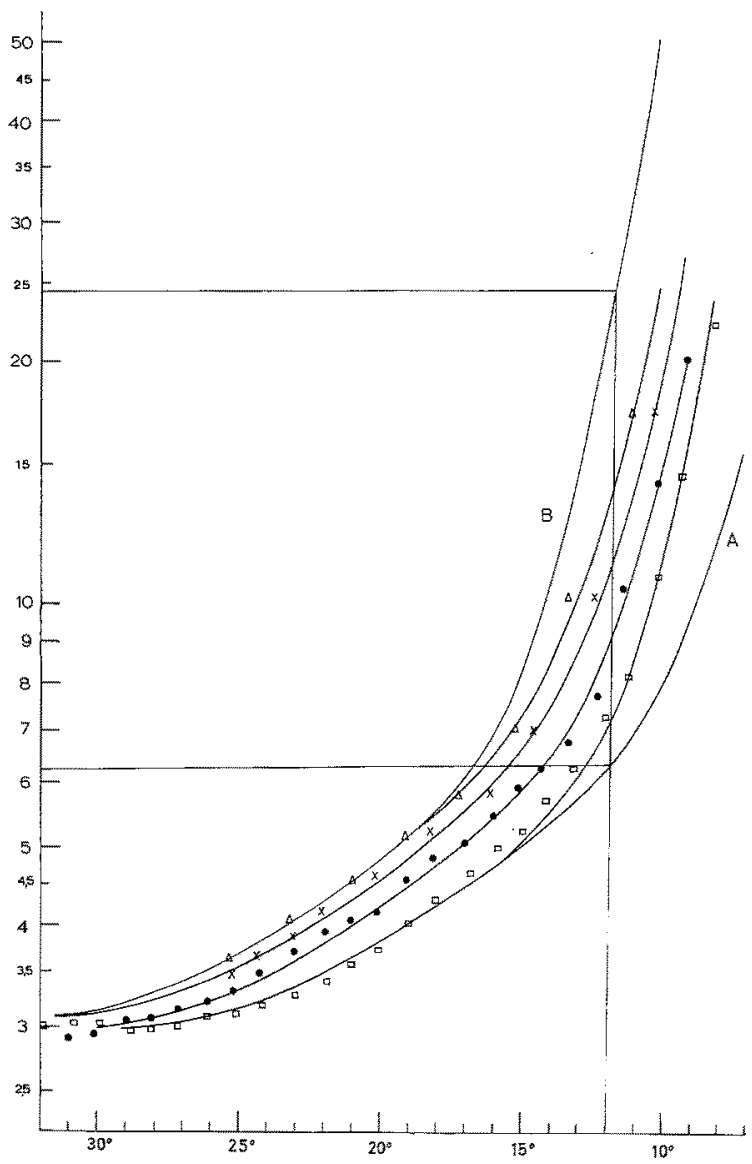

Abb. 2: Umadaptationsversuche an 99 von Xiphophorus helleri (AT: $19^{\circ} \rightarrow 31^{\circ} \mathrm{C}$, Leistungsadaptation). Abszisse: VT $\left({ }^{\circ} \mathrm{C}\right)$; Ordinate: Dauer von 10 Kiemendeckelbewegungen in sec. A: AT-190-Kontrolltiere, B: AT-310 ${ }^{0}$ Kontrolltiere. Die 4 verschiedenen Einzelzeichen sind arithmerische Mittel von jeweils 15 bis 20 Einzelmessungen. $\square$ 1. bis 3. Tag, $\bullet$. bis 6. Tag, $\times 7$. bis 9 . Tag, $\triangle 10$. bis 13 . Tag in $31^{\circ} \mathrm{C}$

die Atmung verwandt (vgl. Prechr 1962). Die Fische waren langfristig an die angegebenen Vorbehandlungstemperaturen angepaßt. Die VT wurde (ausgehend von $\left.25^{\circ} \mathrm{C}\right)$ stetig geändert $\left(0,3^{\circ} / \mathrm{min}\right)$, so daß der zeitliche Verlauf der Anpassung an Hand der ganzen Kurvenverläufe untersucht werden konnte (zur Methodik vgl. THIEDE 1965). Die dort wiedergegebene Abbildung 1 zeigt die Abhängigkeit der Kiemendeckelfrequenz von der AT. Wird diese geändert ( $\mathrm{z}$. B. von $19^{\circ}$ auf $31^{\circ} \mathrm{C}$ ), so ist die 
Umadaptation zwar im oberen Bereich der VT nach 13 Tagen abgeschlossen, jedoch noch nicht im unteren (unter $19^{\circ} \mathrm{C}$ ); für diesen werden etwa 12 weitere Tage benötigt. Bis zum 3. Tag nach der Umsetzung bleiben die Meßwerte im Bereich der VT von $19^{\circ}$ bis $30^{\circ} \mathrm{C}$ ziemlich unverändert auf der Höhe der $1^{0}$-Kontrollen (Abb. 2).

Bei einer Anderung der AT von $25^{\circ}$ auf $31^{\circ} \mathrm{C}$ ergab sich schon am 2. Tag eine Verschiebung der Kurve über den ganzen Bereich der VT. Am 7. Tag war die Umadaptation noch nicht vollständig, was wiederum besonders für den unteren Bereich der VT gilt. Beim Senken der AT von $31^{\circ}$ auf $19^{\circ} \mathrm{C}$ war nach einem Tag schon über den ganzen Bereich der VT ein deutlicher Effekt sichtbar. Vom 30. bis 37. Tag war $z$ war die Umadaptation im oberen Bereich der VT abgeschlossen, jedoch noch nicht im unteren. Auch hier ist der Prozeß der Adaptation selbst temperaturabhängig. Es kommt hinzu, daß die verschiedenen Bereiche der VT unterschiedliche Ergebnisse zeigen.

Wenn das Ausmaß der Anpassung für verschiedene Bereiche der AT unterschiedlich ist, muß dies auch Auswirkungen auf den zeitlichen Verlauf der Anpassung haben (vgl. KLICKA 1965).

KRÜGER (1962) hat bei uns die Umadaptation beim Bitterling (Rhodeus amarus) untersucht, und zwar hinsichtlich der Ganztieratmung, des Sauerstoffverbrauchs des Muskelgewebes (mit Succinat-Zusatz) und der Succinodehydrogenase-Aktivität. In allen Fällen zeigte sich eine Kompensation, am ausgeprägtesten bei der Ganztieratmung. Bei einer Anderung der AT $\left(8^{\circ} \rightarrow 24^{\circ} \mathrm{C}\right)$ fiel die unter gleichen Versuchsbedingungen gemessene Succinodehydrogenase-Aktivität (gemessen nach der THunbergMethode) vom 3. Tag an zunächst rasch und dann immer langsamer $a b$, nachdem sie zunächst zugenommen hatte. Der im WARBURG-Apparat gemessene Sauerstoffverbrauch des Muskelgewebes blieb bis zum 7. Tag nach der Umadaptation konstant, um dann rasch abzufallen. Einen ähnlichen Verlauf nahm die in den ersten Tagen nach der Tem-peraturänderung schwankende Ganztieratmung. Obwohl die Umadaptation in allen drei Fällen etwa am 10. Tag abgeschlossen war, entsprachen sich die zeitlichen Abläufe nicht.

Die Leistungsadaptation kann bei den verschiedensten Lebensprozessen sichtbar sein, nach Boycotr et al. (1961) bei Eidechsen sogar in der Histologie des Zentralnervensystems. Eine besondere Art der Leistungsadaptation scheint bei der biologischen Uhr der Tiere vorzuliegen (vgl. Precht 1964a). Die meisten Autoren nehmen zumindest für die Tagesuhr einen endogenen Rhythmus an, der auf etwa 24 Std. eingestellt ist; die genaue Einregulierung erfolgt durch äußere Zeitgeber (vgl. BünNing 1963, REMMERT 1965 und andere). Die of beobachtete weitgehende Temperaturunabhängigkeit des endogenen circadianen Rhythmus ist eine Vorbedingung für das Funktionieren einer zuverlässigen inneren Uhr. Plötzliche Temperaturänderungen können aber dennoch eine Wirkung haben. Nach BüNNING (1963) kommt es bei einigen Pflanzen auf die Phase des Zyklus an, in der die Temperaturänderung vorgenommen wird. Bei wechselwarmen Tieren scheinen oft einfachere Verhältnisse vorzuliegen. Rasche Temperaturerhöhungen können bei ihnen zu einer vorübergehenden Beschleunigung des endogenen Rhythmus führen, rasche Senkungen zu einer Verspätung (Horfmann 1957, JANKOWSKY 1967a, KASBOHM 1967). Es liegt der Gedanke nahe, daß die innere Uhr deshalb weitgehend temperaturunabhängig ist, weil sie eine rasch verlaufende Leistungsadaptation zeigt, die etwa dem Idealtyp 2 entspricht. Kleine Abweichungen nach 
den Typen 1 und 3 können durch Zeitgeber ausgeglichen werden. Eine solche Adaptation käme dann nur der inneren Uhr zu, nicht den anderen Lebensprozessen des Tieres. Es ist des öfteren beobachtet worden, daß sich die einzelnen Organfunktionen und Zellprozesse hinsichtlich der Leistungsadaptation unterschiedlich verhalten (vgl. FREEman 1950, Vernberg \& Vernberg 1964 und andere). Die Anpassung der Uhr versagt vielfach bei sehr tiefen Temperaturen, was den Gedanken an ein Einfrieren des Adaptationsmechanismus nahelegt, doch wird eine derart einfache Deutung, wie schon früher ausgeführt wurde, wohl nicht allen Beobachtungen gerecht.

Eine weitgehende Temperaturunabhängigkeit besteht auch für andere Rhythmen, wie beispielsweise für die Jahresuhr, was ähnliche Ursachen haben mag. Bei der Schmalwanze Ischnodemus sabuleti ist die Beendigung der Diapause unabhängig von Temperatur und Tageslänge. Der Stoffwechsel kann für die Temperaturunabhängigkeit kaum verantwortlich gemacht werden, da der Sauerstoffverbrauch der Tiere keine Leistungsadaptation zeigt. Vielleicht sprechen manche Tiere auch dann primär auf die endogene Jahresuhr an, wenn sie auf Außenreize - wie die Tageslänge - reagieren. Es kann nämlich sein, daß durch derartige Reize zunächst die Uhr verstellt wird. Während der Diapause der Wanze mag die Wirkung der Tageslänge auf die Uhr blockiert sein, wodurch der endogene Rhythmus dann deutlich wird.

Die Leistungsadaptation kann komplizierter verlaufen, wenn man nicht nur die Temperatur von Vorbehandlung und Versuch berücksichtigt, sondern damit zusammen andere Faktoren variiert, zum Beispiel die Belichtungsverhältnisse. Diese Probleme hat neuerdings KASBOHM (1967) für den Sauerstoffverbrauch intakter of von Rana temporaria untersucht.

\section{Extremer Temperaturbereich}

Vorübergehende Phänomene

\section{Erstreaktionen, Schocks}

Wie bei den over- und undershoots kommt es bei der Messung der Resistenz der Tiere gegenüber extremen Temperaturen (speziell in Versuchen, bei denen stetig steigende beziehungsweise fallende Temperaturen angewandt werden) auf die Geschwindigkeit der Temperaturänderung an (vgl. PrECHT et al. 1955, pp. 45, 56). Dies gilt schon für Einzeller. MAzUR (1961) fand zum Beispiel bei Messungen der Kälteresistenz von Saccharomyces, daß rasches Abkühlen und langsames Auftauen die Letalität erhöht (vgl. auch ATA \& STAIB 1957). Ein Abkühlen auf tiefe Temperaturen, das zu Verglasungen führt, ist gesondert zu betrachten.

Auch für höhere Organismen ist dies Problem untersucht worden. Für den Guppy (Lebistes reticulatus) fanden TsukUdA \& OHSAWA (1958) folgendes: The heat coma temperature falls and the cold coma temperature rises hyperbolically as the rate (of the change of temperature) decreases (p. 76, vgl. auch SumNer \& Doudoroff 1938, p. 422, Watanabe 1950, Love \& Whelchel 1957, Bishai 1965). Eine rasch verlaufende Resistenzadaptation kann bei derartigen Versuchen stören (vgl. Hutchison 1961, p. 100). 
Die zu beobachtenden Verhaltenssymptome können bei den Erstreaktionen oder Schocks von der Adaptationstemperatur beeinflußt werden. So tritt in Experimenten, bei denen die Temperatur laufend gesteigert wird, bei Karauschen eine Maulsperre nur bei den warmadaptierten auf, nicht bei den kaltadaptierten, und zwar deshalb, weil diese Reaktion kaum von der AT abhängt und bei Temperaturen auftritt, die von den kaltadaptierten Tieren nicht erreicht werden (CHRISTOPHersen \& PRECHT 1952).

Auch für den von uns in mehrfacher Hinsicht untersuchten Nerfling (Idus idus) konnte WILKE den Einfluß der Erhitzungsgeschwindigkeit auf die Hitzeresistenz nachweisen (Versuchszeit Januar bis Februar, Länge der Fische: 11 bis $13 \mathrm{~cm}$, AT: $6^{\circ} \mathrm{C}$, 16 Std. Langtag). Zwei bis drei Tiere befanden sich bereits 2 Std. vor den Messungen in größeren Glasröhren, durch die das zu erwärmende Wasser langsam strömte (Ausgangstemperatur $6^{\circ} \mathrm{C}$ ). Beobachtet wurden auftretende Ausbruchsversuche, Taumelbewegungen und die Einnahme der Rückenlage (selten traten dabei Drehungen um

Tabelle 2

Abhängigkeit der Hitzeresistenz von Goldorfen (Idus idus) von der Erhitzungsgeschwindigkeit (angegeben in ${ }^{\circ} \mathrm{C} / \mathrm{min}$ ). Vermerkt sind die Temperaturen mit den mittleren Fehlern der Mittelwerte, bei denen die betreffenden Symptome auftraten

\begin{tabular}{|c|c|c|c|c|c|}
\hline \multirow{2}{*}{$\begin{array}{l}\text { Geschwindig- } \\
\text { keit der Tem- } \\
\text { peratur- } \\
\text { steigerung }\end{array}$} & \multirow{2}{*}{$\begin{array}{l}\text { Ausbruchs- } \\
\text { versudhe } \\
\left({ }^{\circ} \mathrm{C}\right)\end{array}$} & \multirow{2}{*}{$\begin{array}{c}\text { Taumel- } \\
\text { bewegungen } \\
\left({ }^{\circ} \mathrm{C}\right)\end{array}$} & \multicolumn{2}{|c|}{ Rückenlage } & \multirow{2}{*}{$\underset{\text { Tiere }}{\text { Anzahl }}$} \\
\hline & & & $\left({ }^{\circ} \mathrm{C}\right)$ & P-Werte & \\
\hline 0,3 & $23,4 \pm 0,30$ & $25,7 \pm 0,20$ & $27,2 \pm 0,15$ & $<0,0002$ & 9 \\
\hline 0,6 & $25,9 \pm 0,41$ & $26,3 \pm 0,45$ & $29,4 \pm 0,19$ & & 8 \\
\hline
\end{tabular}

die Längsachse auf); alle Fische erholten sich nach diesen Versuchen. Einzeln gemessene Tiere zeichneten sich durch eine größere Unruhe aus. Die Temperaturen, bei denen die verschiedenen Merkmale auftreten, nehmen mit steigender Erhitzungsgeschwindigkeit zu (Tab. 2).

\section{"Hardening" (Scbockanpassung)}

Über das hier zu diskutierende Phänomen haben besonders Botaniker (vor allem Alexandrov 1964 und seine Mitarbeiter) gearbeitet. Zunächst sei über das „heatharden ing" berichtet. Es handelt sich um eine Hitzeresistenzerhöhung, wenn man die Pflanzen sehr hohen (möglichst subletalen) Temperaturen aussetzt. Nur hohe Temperaturen haben einen Effekt (Abb. 3), doch dürfen diese nicht zu lange einwirken (Abb. 4). Die Erhöhung der Resistenz zeigt sich meist sehr bald nach einer solchen Behandlung, so daß sofort eine Schutzwirkung gegeben ist; Schroeder (1965) fand dagegen eine deutliche Steigerung erst in den folgenden Tagen. Mit der Hitzeresistenz steigt die Widerstandsfähigkeit gegenüber anderen schädigenden Faktoren, bei Blattepidermiszellen von Tradescantia fluminescens zum Beispiel gegenüber Alkohol, Essigsäure und hohen Drucken (besonders Faktoren, die Eiweiße denaturieren, Lomagin et al. 1964), nicht jedoch gegeniber Ammoniak und extrem tiefen Tempera- 
turen (Denko 1964). Von der Anpassung werden mehrere Zellfunktionen betroffen, beispielsweise die Plasmaströmung, die Photosynthese und Atmung (Feldman et al. 1964). Die Photosynthese nimmt dabei in ihrer Hitzeresistenz zu, aber in ihrer Intensität $a b$; bei der Rückführung in die Ausgangstemperatur wird die alte Intensität schneller wiederhergestellt als die Resistenz, deren Erhöhung längere Zeit anhält. Durch
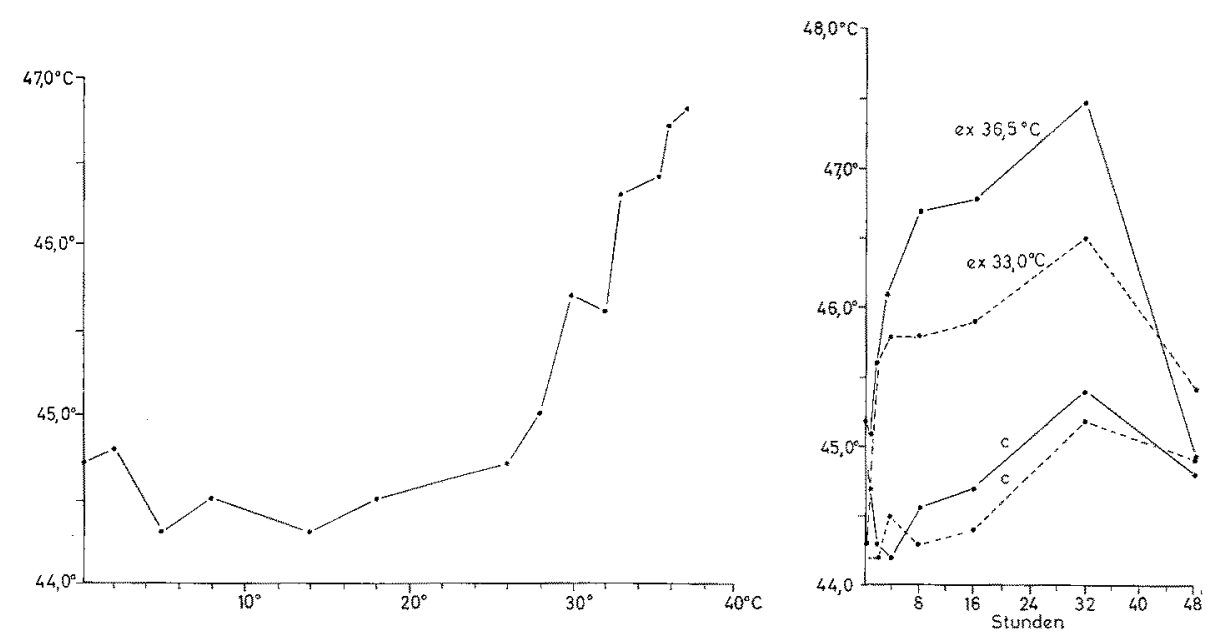

Abb. 3: Einfluß der hardening-Temperatur (Abszisse) auf die Hitzeresistenz (Aufhören der Protoplasmabewegung nach einer Einwirkung der auf der Ordinate angegebenen Temperatur für $5 \mathrm{~min}$ ) von Blattepidermiszellen von Tradescantia fluminescens (Dauer des hardening 16-18 Std.; nach Alexandrov \& Feldman aus Alexandrov 1964)

Abb. 4: Einfluß der Dauer des hardening in Std. (Abszisse) auf die Hitzeresistenz der Epidermiszellen von Tradescantia fuminescens (Ordinate wie in Abb. 3). $\mathrm{c}=$ Kontrollen, ex: Blatthälften nach einem hardening bei $33,0^{\circ}$ und $36,5^{\circ} \mathrm{C}$ (nach AleXandrov \& FELDMAN aus ALEXANDROV 1964)

das heat-hardening sollen die Zellproteine stabilisiert werden. Dafür in Betracht kommende Möglichkeiten (, a change in structure of proteins, the appearance of antidenaturants, the acceleration of protein resynthesis and renaturation ") werden diskutiert (Feldman et al. 1964). Eine Resistenzadaptation in Form einer Hitzeanpassung, das heißt eine Adaptation an A'Ts des normalen Temperaturbereichs, kommt ebenfalls bei Pflanzen vor, nach neueren Befunden der Mitarbeiter von Alexandrov bei Algen und nach LANGe (1961) auch bei höheren Pflanzen. Eine noch nicht schädigende Hitzeeinwirkung soll bei einigen Pflanzen auch zu einer Herabsetzung der Widerstandsfähigkeit gegenüber hohen Temperaturen führen (YAR WOOD 1965 und andere).

Kommt ein "heat-hardening" auch bei Tieren vor? Hutchison (1961) fand, daß bei einer zweiten Bestimmung des critical thermal maximum sofort nach der ersten die Hitzeresistenz zunahm. Bei einer Verlängerung der Zwischenzeit wurde die Resistenzerhöhung auf Grund der ersten Temperatureinwirkung immer weniger deutlich. Es ist bei den Urodelen, welche als Versuchstiere dienten, zu berücksichtigen, daß die Resistenzadaptation schnell verläuft (vgl, jedoch auch BRATTSTROM \& LAWRENCE 1962, 
p. 152, Heatwole et al. 1965); erste Versuche dieser Art führten bereits Fry et al. (1946, p. 28) aus. Russische Autoren bemerkten auf dem Leningrader Symposium (1963), auf dem die Botaniker dies Problem eingehend diskutierten, daß ein hardening auch bei Tieren vorkomme (nach Astaurov bei Seidenspinnereiern, nach SCHLACHTER \& Chernokozheva bei isolierten Froschmuskeln nach Hitzeschocks von 5-10 min). Diese Resistenzänderungen zeigten sogar jahreszeitliche Unterschiede. Hingewiesen sei auch auf die Versuche von House et al. (1958) an Insektenlarven (vgl. I. Precht 1967).

Uber ein "cold-hardening" ist weit weniger bekannt als über das heat-hardening. Alexandrov führt als Beispiel die Frostabhärtung der Pflanzen an, über die viele Untersuchungen vorliegen (vgl. Levrtt 1956, Ulcrich 1962, Tumanov 1964, Tumanov et al. 1965 und andere). Manchmal wird gar kein Frost vertragen, so daß man dann besser von einer Kälteabhärtung spricht. Es fragt sich aber, ob man die Frost- und Kälteabhärtung der Pflanzen nicht besser als Kälteadaptation auffaßt und sie damit der Resistenzadaptation zuordnet.

Man muß auch bei der Erlangung einer hohen Kälteresistenz bei Pflanzen Wirkungen der Vorbehandlungstemperatur und eventuell hinzukommende temperaturunabhängige jahreszeitliche Anderungen der Widerstandsfähigkeit unterscheiden. Es kommt als Komplikation hinzu, daß das Ausmaß der Wirkung der AT sich jahreszeitlich ändern kann. Sehr exakt sind diese Faktoren von PISEK bei seinen Untersuchungen über Fichtennadeln getrennt worden (vgl. PRECHT et al. 1955, p. 81). Abhär-" tend wirken oft nur relativ tiefe T'emperaturen (zum Beispiel unter $5^{\circ}$ bis $10^{\circ} \mathrm{C}$, vgl. LEvitT 1956, p. 49). Trunova (1964) fand bei der Abhärtung von Wintergetreide alle Temperaturen von $15^{\circ}$ bis $-3^{\circ} \mathrm{C}$ wirksam. Bei einer Vorbehandlungstemperatur von $15^{\circ}$ betrug der Resistenzgewinn 2 bis $3^{\circ}$, bei $0^{0}$ jedoch $18^{\circ}$. Es handelt sich um ein bleibendes Phänomen, durch das im Zusammenwirken mit anderen Anpassungen die Pflanzen die kalte Jahreszeit überstehen sollen. Für diese Zeit gehören die anzuwendenden Temperaturen zum "normalen " Bereich und nicht zum subletalen. Die Abhärtung tritt auch für gewöhnlich erst nach einer längeren Einwirkung der niederen Temperaturen ein, zum Beispiel nach Messungen von Denko (1964) bei Cabomba aquatica nach einer Überführung von $20^{\circ}$ in $5^{\circ} \mathrm{C}$ nach 10 bis 20 Tagen und in $10^{\circ}$ nach 20 bis 30 Tagen. All dies spricht dafür, daß es sich um eine Kälteadaptation handelt, wie sie noch besprochen wird, und nicht um ein dem heat-hardening vergleichbares cold-hardening, wobei unterstellt wird, daß eine Unterscheidung der Schockanpassung von der Resistenzadaptation gerechtfertigt ist. Dann ist aber der Name hardening etwas unglücklich gewählt worden, da man an die stets als hardening bezeichnete Kälteabhärtung der Pflanzen im Winter denkt.

Die von Doudorofs (1942) untersuchten Fische (Girella) wurden zunächst für 5 Tage hitzeresistenter, als er die AT senkte $\left(26^{\circ} \rightarrow 14^{\circ} \mathrm{C}\right)$. Man könnte dies vielleicht so deuten, daß hier zunächst ein cold-hardening vorgelegen hat, welches sich im Gegensatz zur Resistenzadaptation gegenüber hohen Temperaturen paradox verhält; nach einiger Zeit hat sich dann eine gegenüber beiden Extremtemperaturen sinnvolle Kälteadaptation durchgesetzt. Dieser Fall müßte genauer untersucht werden.

Wir beruhren mit diesem Beispiel eine mehrfach angewandte Unterscheidung von "spezifischen" und "unspezifischen" Anpassungen. Im ersten Fall liegt eine Adaptation an einen bestimmten Faktor vor, im letzten eine ganz allgemeine Resistenzveränderung 
gegenüber vielerlei Faktoren, so auch gegenüber beiden Extremtemperaturen. Für die uns hier interessierende Unterscheidung der Schockanpassung (hardening) von der Resistenzadaptation ist jedoch der Grad der Spezifität ungeeignet. Weitgehend unspezifisch ist die Kälteabhärtung der Winterpflanzen, da mit der Kälteresistenz of auch die Hitzewiderstandsfähigkeit steigt, ferner die Dürreresistenz etc. Unspezifisch steigt bei der Hefe Torulopsis kefyr mit steigender Züchtungstemperatur nicht nur die Hitze-, sondern auch die Kälteresistenz (Christophersen \& Precht 1956). Nicht ganz unspezifisch ist das heat-hardening der Pflanzen, da die Kälteresistenz nicht betroffen ist, aus demselben Grunde ebensowenig die Hitzeadaptation von Fischen, obwohl die warmadaptierten Tiere nicht nur gegenüber hohen Temperaturen, sondern auch gegenüber vielen anderen Faktoren (Sauerstoffmangel, Giften, Narkotika etc.; vgl. Sumner \& Doudoroff 1938, Schlieper \& Kowalski 1956, Schlieper 1960 , v. Buddenbrock 1960, Basu 1959 und andere) resistent sind. Nach Pitkow (1960) wurden von den bei $23^{\circ} \mathrm{C}$ gehaltenen Lebistes reticulatus nicht nur tiefe Temperaturen, sondern auch eine herabgesetzte Sauerstoffspannung besser vertragen als von den bei $30^{\circ}$ gehaltenen Tieren. Wenn man hier von einer unspezifischen Resistenzzunahme mit fallender AT sprechen will, muß man die Hitzeresistenz ausklammern. Schon bei den Versuchen von Sumner \& Doudorofr (1938) an Gillichthys lief die Anderung der $\mathrm{KCN}$-Resistenz nicht der der Hitzeresistenz zeitlich parallel, wenn die AT von $20^{\circ}$ auf $30^{\circ} \mathrm{C}$ erhöht wurde. Die Anderung der Urethanempfindlichkeit nach einem Wechsel der AT verlief bei den an Fischen durchgeführten Versuchen von SUMNER \& WELLS (1935) viel schneller als die gegenüber KCN und Sauerstoffmangel. Das Problem einer allgemeinen Resistenz darf somit nicht zu einfach gesehen werden. Insekten zeigen vielfach nur eine Kälte- und keine Hitzeadaptation; es wird also nicht die Resistenz ganz allgemein geändert. Nach VERNBERG et al. (1963) komme es auf die natïrlichen Temperaturverhältnisse im Biotop an, ob bei einer Art die kalt-oder warmadaptierten Tiere besonders resistent gegenüber anderen Faktoren sind.

Wir sprechen bei der Resistenzadaptation von einer sinnvollen (reasonable) Anpassung, wenn die Hitzerestistenz- und Kälteempfindlichkeit mit steigender AT zunehmen, im umgekehrten Fall von einer paradoxen Adaptation. Eine gänzlich unspezifische Anpassung ist stets sinnvoll gegenüber der einen Extremtemperatur und paradox gegenüber der anderen und niemals sinnvoll gegenüber beiden Extremtemperaturen, wie dies bei den Fischen der Fall ist. Die Ausdrücke sinnvoll und paradox, die nicht in einem teleologischen Sinne verstanden werden sollen, könnten sinngemäß auch für das hardening angewandt werden, sofern diesem ein Sondercharakter zukommt und eine Trennung von der Resistenzadaptation notwendig ist.

Eine Schockanpassung kann eigentlich nur die biologische Bedeutung haben, daß die Resistenz gegenüber extremen Temperaturen als rasch verlaufende Schutzmaßnahme schnell gesteigert wird. Es taucht sogar der Verdacht auf, daß das hardening bei gewissen Methoden ( $\mathrm{z}$. B. der Messung der Resistenz durch langsames Steigern oder Senken der Temperatur) deshalb übersehen wird, weil es sich schon wathrend des länger dauernden Versuchs abspielt. Wenn bei derartigen Messungen eine Resistenzadaptation deutlich zutage tritt, so könnte sie durch sehr rasche Anpassungseffekte höchstens in ihrem Ausmaß verändert worden sein.

Es seien zunächst einige Fälle einer sehr raschen Resistenzänderung bei einer An- 
derung der AT' betrachtet. Ciliaten zeigen, wie neuerdings Vogel (1966) an Zoothamnium biketes bestätigen konnte, eine echte Resistenzadaptation im Sinne einer sinnvollen Anpassung an beide Extremtemperaturen. Die Anpassung an die obere Resistenzgrenze dauerte 3 bis 5 Tage; Poljansky fand dagegen bei Ciliaten schon Anpassungseffekte nach einer Stunde (Literatur bei Alexandrov 1964, p. 60, Vogel 1966). PRECHT (1960a) konnte die Hitzeresistenz der Endplattenïbertragung von NervMuskel-Präparaten warmadaptierter Grasfrösche durch eine Aufbewahrung für einige Stunden bei tiefen Temperaturen steigern (vgl. hierzu Thörner 1920, Yamada 1924), die Hitzeresistenz des Muskels wurde jedoch nicht geändert. Das Cilienepithel der Fühlerspitzen der Posthornschnedke Planorbis corneus weist nach einer langfristigen Anpassung der Tiere an verschiedene Temperaturen eine sinnvolle Kälteadaptation auf (Precht \& Christophersen 1965). In Umadaptationsversuchen wurden entweder die Schnecken von $22^{\circ}$ in $8,5^{\circ} \mathrm{C}$ überführt, wobei wir jeweils den einen Fühler des Tieres vor der Uberführung, den anderen nach der Anpassung untersuchten, oder wir adaptierten die isolierten Fühler für 3 Tage um. In beiden Fällen nahm die Kälteresistenz etwa um den gleichen Betrag zu.

Inzwischen hat BERECK den zeitlichen Verlauf der Umadaptation gemessen, wobei wiederum einmal die Schnecken, zum anderen die isolierten Fühler in eine neue AT umgesetzt wurden (Versuchszeit: August bis Oktober, Versuchstiere: die von PRECHT \& Christophersen benutzte Rasse $\mathrm{R}_{2}$, Aufbewahrung unter Langtagsbedingungen). Nach einer zweiwöchigen Anpassung an $22^{\circ} \mathrm{C}$ wurde zunächst die Kälteresistenz jeweils eines abgeschnittenen Fühlers bestimmt, worauf wir die Schnecke beziehungsweise den anderen isolierten Fühler plötzlich in $5^{\circ} \mathrm{C}$ überführten. Die Tiere zogen sich nach dem Temperatursprung zunächst teilweise in das Gehäuse zurück, doch zeigten sie nach einer Minute bereits wieder ein normales Verhalten. Die abgeschnittenen Fühler gelangten in die schon früher benutzte Lösung von BENEX (1961). Die Variabilität der Meßwerte konnte dadurch stark herabgesetzt werden, daß wir nur die Kälteresistenz der beiden Fühler desselben Tieres miteinander verglichen und diese kurz vor der Resistenzmessung auf eine einheitliche Länge $(0,5 \mathrm{~mm})$ zuschnitten.

Zur Methode sei noch erwähnt, daß die Abkühlungszeit bis zur unteren Grenztemperatur im Durchschnitt $9,5 \mathrm{~min}$ dauerte, wenn wir von $5^{0}$ ausgingen, etwa $20 \mathrm{~min}$ bei einer Ausgangstemperatur von $22^{\circ} \mathrm{C}$. $\mathrm{Da}$ sich kein nennenswerter Unterschied hinsichtlich der Letaltemperatur zeigte, ist stets $5^{\circ} \mathrm{C}$ als Ausgangstemperatur gewählt worden. Das Sistieren des Wimpernschlags bei fallender Temperatur beginnt an der Spitze der Fühler und schreitet mit sinkender Temperatur allmählich bis zur Basis (also der Schnittstelle) fort. Als Meßpunkt diente die Temperatur, bei der die Cilien nahe der Schnittstelle ihre Schlagfrequenz deutlich verringern, um wenig später stillzustehen.

Die isoliert in $5^{\circ} \mathrm{C}$ überführten Fühler zeigten bereits nach einer Stunde eine statistisch gesicherte Senkung der unteren Grenztemperatur um 3,9 $\pm 0,9^{\circ}$ (25 untersuchte Tiere, $P=0,003$ ). Beim erst kurz vor der Messung abgeschnittenen zweiten Fühler der umadaptierten Schnecken betrug der Unterschied zum anderen Fühler eine Stunde nach der Überführung von $22^{\circ}$ in $5^{\circ} \mathrm{C} 1,7 \pm 0,4^{0}$ (32 Tiere, $P<0,0002$ ). Erstaunlich schnell verlief bei den Versuchen von BERECK auch die Abnahme der Kälteresistenz des Cilienepithels nach einer Rückführung der isolierten Fühler von $5^{0}$ in 
$22^{\circ} \mathrm{C}$. Es genügte wiederum eine Stunde zur Erreichung der alten Resistenzwerte. Ein Umadaptationsversuch $\left(5^{\circ} \rightarrow 22^{\circ} \mathrm{C}\right)$ mit Schnecken erbrachte in einer Stunde eine Abnahme der Kälteresistenz von $0,6 \pm 0,2^{\circ}$ (29 Tiere, $P=0,0004$ ). Nach zwei Stunden war der alte Resistenzwert der $22^{\circ}$-Tiere erreicht. Es handelt sich bei diesen Vorbehandlungstemperaturen um den "normalen" Bereich, doch ist der Temperatursprung bei Überführungen relativ groß, so daß Schockwirkungen resultieren können. Bei den Versuchen von PRECHT \& CHRISTOPHERSEN (1965) wurde die Kälteadaptation nach langfristiger Anpassung gemessen, somit nicht unbedingt dasselbe Phänomen wie von BERECK.

Die Verwendung des Zeitfaktors als eindeutiges Unterscheidungsmerkmal zwischen der Hitzeadaptation und dem heat-hardening stößt deshalb auf Schwierigkeiten, weil der Mechanismus der ersten stark temperaturabhängig sein kann, so daß die Anpassung bei hohen Temperaturen rasch verläuft. Wenn kurze Kälteschocks jedoch einen Effekt haben, spricht dies für ein cold-hardening.

Beim hardening werden für gewöhnlich subletale Temperaturen angewandt, in denen die Objekte nicht bleiben. Man kann Blätter von Campanula persifolia aber auch in sehr hohe Temperaturen überführen und darin belassen. Die Plasmabewegung hört nach 90 min ganz auf, fängt jedoch später auf Grund einer Resistenzzunahme wieder an (AlEXANDrov 1964). Es wird betont, daß nur hohe Temperaturen einen Effekt haben; bei den niedrigen der Abbildung 3 könnte aber einfach die Zeit der Einwirkung zu kurz gewesen sein, so daß nur eine temperaturabhängige Geschwindigkeit einer Resistenzadaptation vorgelegen haben kann. Selbst wenn man feststellt, daß nur hohe Temperaturen eine Resistenzänderung bewirken, nicht solche des normalen Temperaturbereichs, so braucht dies zunächst nicht mehr zu bedeuten, als daß die Hitzeadaptation auf einen bestimmten (in diesem Fall den oberen) Bereich der AT beschränkt bleibt. Auch die Leistungsadaptation ist manchmal nur in einem bestimmten Bereich der AT festzustellen (RoberTs 1964 und andere). Nach Brshai (1965) soll die Hitzeresistenz der meisten Altersstufen des Fisches Tilapia nilotica von der AT abhängen, die der frühen Larvenstadien wird jedoch nur von ATs über $35^{\circ} \mathrm{C}$ beeinflußt. Tenebrio molitor-Larven zeigen nach MeLLANBy (1954) bei Vorbehandlungstemperaturen über $30^{\circ} \mathrm{C}$ eine sinnvolle Hitzeadaptation, bei solchen unter $30^{\circ}$ keine. Nach BALDwIN (1954) kann die Hitzeadaptation in einem Bereich der AT sinnvoll verlaufen, in einem anderen paradox (vgl. die Zusammenstellung von I. Precht 1967). Bei Fischen verläuft die Hitzeanpassung durchweg sinnvoll, doch kann sie in sehr hohen Bereichen der AT fehlen (BRETT 1956 und andere). Eine Beschränkung auf sehr hohe und sehr tiefe Temperaturen deutet andererseits darauf hin, $\mathrm{daß}$ hier ein Sonderphänomen vorliegt, das zu dem stress-Problem überleitet (vgI. p. 388).

Es ist oftmals nicht gelungen, bei intakten Tieren ein hardening nachzuweisen, bei denen es ja allein einen biologischen Nutzen haben könnte. Mehrfach wurde keine Resistenzänderung gegenüber extremen Temperaturen gefunden, wenn man die erste Bestimmung der Resistenz (die als Schock wirken mïßte) mit denselben Tieren wiederholt. TsukudA (1959) maß bei Lebistes (AT $25^{\circ} \mathrm{C}$ ) die Kältekomatemperatur derselben Individuen an jedem Tag oder sogar in Intervallen von $90 \mathrm{~min}$. Im ersten Fall änderte sie sich wenig, im zweiten Fall nahm sie zu (Abnahme der Resistenz). I. PRechr (1967) 
fand keine Anderung für die Hitzeresistenz von Deroceras reticulatum und Carausius morosus bei wiederholter Messung. Entsprechendes gilt für die Kälteresistenz der Stabheuschrecke. Dieses Insekt zeigt auch keine Hitze- und Kälteadaptation, die Nacktschnecke dagegen eine sinnvolle Hitzeanpassung.

Basedow hat sich um den Nachweis eines hardening bei Fischen bemüht (Goldorfen, Idus idus L., 3 Größenklassen: 4,5, 9,5 und $13 \mathrm{~cm}$; Steigaale, Anguilla vulgaris L., Länge 7 bis $10 \mathrm{~cm}$; Schwertträger, Xiphophorus helleri Heckel, Länge 4 bis $5 \mathrm{~cm}$ ). Gemessen wurde die Hitze- und Kälteresistenz intakter 'Tiere durch Bestimmung der Temperaturen, bei denen durch Aufheizen beziehungsweise Abkühlung des Wassers bestimmte Kriterien auftraten, die anzeigten, daß die Fische unfähig waren, die für sie ungünstige Umgebung zu verlassen (critical thermal maximum and minimum, nach HuTCHISON 1961). Diese Kriterien waren: für Idus (Hitze und Kälte) Unfähigkeit, die normale Gleichgewichtslage zu halten (Rückenlage), für Anguilla (Hitze und Kälte) endgültige Bewegungslosigkeir (der Schwerpunkt des Aales bedingt dann keine Rückenlage), für Xiphophorus (Hitze) das Einnehmen der Rückenlage sowie Abspreizen der Brustflossen und (Kälte) plötzliche heftige Bewegungen mit darauffolgender Kältestarre (abgespreizte Brustflossen).

Bei diesen Versuchen maßen wir zunächst bei etwa 8 Kontrolltieren die Hitzeund Kälteresistenz. Sodann haben wir eine Anzahl von Fischen aus derselben AT auf $0,5^{0}$ unter beziehungsweise uiber den errechneten Mittelwert der kritischen Temperatur aufgeheizt oder abgekühlt, worauf wir die Fische durch schnelles Abkühlen oder Aufheizen $(1 \% / \mathrm{min})$ in die AT' oder die gew ünschte Temperatur zurückführten (Methode I). In anderen Versuchen überführten wir die Tiere direkt in hohe beziehungsweise tiefe Temperaturen und beließen sie darin (Methode II). Wir ermittelten dann die Resistenz dieser Tiere (stets mit anderen Individuen) in den ersten 24 Std. häufiger und darauf alle weiteren 24 Std. Für einen Meßpunkt wurden meist 8 Tiere verwendet. (Eine genaue Schilderung der Methoden und Ergebnisse erfolgt an anderer Stelle.)

Methode I: Es zeigte sich bei Orfen und Schwertträgern, daß die Schockbehandlung mit hohen Temperaturen die Hitzeresistenz der beiden Arten geringfügig steigerte $\left(0,5^{\circ}\right.$ oder etwas mehr), was bis zum 4 . Tag deutlich war, dann aber zurückging. Die Kälteresistenz wird nicht verändert (Goldorfen) oder sie nimmt etwa parallel zum Anstieg der Hitzeresistenz ab (Schwertträger). Die Kälteadaptation verläuft bei $l d u s$ wie bei anderen Fischen sinnvoll, was im Gegensatz zu diesem Versuch steht. Es wäre jedoch voreilig, dies auf die Folgen eines heat-hardening zurüdkzuführen. Hitze- und Kälteadaptation werden sicherlich auch bei diesem Fisch durch zwei Mechanismen gesteuert; somit genügt zur Erklärung des Befundes die Annahme, daß die Kälteadaptation weniger empfindlich auf die kurze Einwirkung hoher Temperaturen anspricht als die Hitzeadaptation. Eine entsprechende Schockbehandlung mit tiefen Temperaturen hatte auf die Hitze- und Kälteresistenz beider Arten keinen Einfluß.

Methode II: Abrupte Umsetzungen in hohe Temperaturen, die für längere Zeit vertragen werden, ließen die Hitzeresistenz und Kältempfindlichkeit sehr rasch ansteigen, und zwar um so schneller, je größer der Temperatursprung war (Aale und Orfen) und je höher die Temperatur war, in welche die Tiere überführt wurden. Die Ergebnisse beweisen nur die Temperaturabhängigkeit der Umadaptationsgeschwindigkeit. Es zeigte sich kein anfänglicher Gipfel in den Kurven, der ein rasch verlaufendes heat- 
hardening angezeigt hätte, welches zunächst die Resistenz über den durch die Resistenzadaptation bedingten Wert gesteigert hätte.

Bei Umsetzungen in tiefe Temperaturen nahm die Hitzeresistenz der Aale sehr langsam $a b$, ihre Kälteresistenz steigerte sich etwas schneller, was wiederum für zwei Adaptationsmechanismen spricht. Auch bei diesen Versuchen fand sich kein Hinweis für ein cold-hardening. Bei Idus zeigte ein Versuch, bei dem die Tiere von $22^{\circ}$ in $12^{\circ} \mathrm{C}$ umgesetzt wurden, hinsichtlich der Hitzeresistenz ein entsprechendes Ergebnis.

Weitere Versuche hat WILKE mit dem epizoisch auf Gammariden lebenden Ciliat Zoothamnium biketes PRECHT durchgeführt, dessen Resistenzadaptation Vogel (1966) untersuchte.

Wir hielten die bei Kiel gefangenen, besiedelten Krebse in gut durchlüftetem Fördewasser bei $15^{\circ}$ bis $17^{\circ} \mathrm{C}$ (Versuchszeit August bis Oktober). Zur Messung der Hitzeresistenz des Ciliaten steckten wir die besiedelten Hinterenden der Krebse mit Insektennadeln auf einem Stück Knetmasse im Versuchsgefäß (Durchmesser $4,5 \mathrm{~cm}$ ) fest. Dieses bestand aus Aluminium und wurde von Wasser umspült, das wir mit einer konstanten Geschwindigkeit aufheizten $(0,3 \% \mathrm{~min})$. Ein auf dem Boden des Gefäßes im Winkel von etwa $45^{\circ}$ angebrachter Spiegel ermöglichte eine genaue Beobachtung der Versuchstiere mit einer binokularen Lupe im Durchlicht.

In einer ersten Versuchsserie untersuchten wir das Erlöschen der mit einer feinen Borste auslösbaren Stielmuskelkontraktion, die nach VoGeL bei derartigen Versuchen nur eine schwach ausgeprägte Hitzeadaptation aufweist. Deutlicher war diese festzustellen, wenn Vogel die Zeit maß, die unterschiedlich adaptierte Tiere bei $34^{\circ} \mathrm{C}$ bis zum Erlöschen der Kontraktion aufbewahrt werden konnten.

In Kontrollmessungen stellten wir zunächst die obere Grenztemperatur für die Stielmuskelfunktion fest; sie betrug im Durchschnitt 35,50 C. Danach führten wir mit neuen Tieren Versuche durch, bei denen die Temperatur nur bis $34^{\circ} \mathrm{C}$ stieg. War diese Temperatur erreicht, kühlten wir das Wasser wieder langsam ab (ca. 10/min), bis die Ausgangstemperatur erreicht war. Alle Tiere überlebten und bei allen war die Stielmuskelkontraktion gut auslösbar. Bei den so vorbehandelten Tieren wurde in verschiedenen Gruppen die obere Grenze der Kontraktionen bestimmt, und zwar entweder sofort im Anschluß an die erste Erwärmung oder nach 2, 3,5, 4, 16, 17, 18 und 24 Stunden. Es konnte kein Resistenzgewinn gegenüber den Kontrollen festgestellt werden.

Weitere Versuche haben wir in der Weise durchgeführt, daß die mit Zoothamnien besiedelten Krebshinterenden von ihrer AT direkt in die subletale Temperatur von $34^{\circ} \mathrm{C}$ überführt wurden. Nach $5 \mathrm{~min}$ haben wir sie ebenso abrupt in die Ausgangstemperatur zurückversetzt. Anschließend erfolgte die langsame Erwärmung zur Feststellung der oberen Grenze der Stielmuskelfunktion. Auch bei dieser Versuchsausführung zeigte sich kein signifikanter Unterschied zu den Kontrollen.

Schließlich benutzten wir eine dritte Methode zur Bestimmung der Lebensresistenz der Zoothamnien, die nach VoGel ebenfalls von der AT abhängt. Zur Vorbehandlung bewahrten wir die Tiere für 5 beziehungsweise 15 min bei $34^{\circ} \mathrm{C}$ auf (plötzliche Uberführung und Rückversetzung). Je 10 so vorbehandelte und nichtbehandelte Krebsurosome mit Ciliaten erwärmten wir langsam $\left(0,3^{\circ} / \mathrm{min}\right)$. Ab $34^{\circ} \mathrm{C}$ und jeweils $0,3^{\circ}$ höher überführten wir ein geschocktes und ein nichtbehandeltes Urosom in $25^{\circ} \mathrm{C}$ 
und prüften später die Zahl der überlebenden Zoothamnien. Die Schockbehandlung hatte auch auf die Lebensresistenz keinen Einfluß.

Bei all diesen Versuchen haben wir nur so hohe Schocktemperaturen verwendet, daß sie gerade noch für sehr kurze Zeiten vertragen werden können; wir haben nur solche Temperaturen gewählt, an die eine Schockanpassung noch eine gewisse biologische Bedeutung gehabt hätte. Zur Zeit führen wir Versuche mit Polypen von Cnidariern durch und verwenden dabei auch sehr hohe Temperaturen, die nur noch als kurzdauernder stress wirken können.

Es spricht eindeutig für den Sondercharakter des hardening, wenn dieses anders abläuft als die Resistenzadaptation. Das von PRECHT untersuchte Nerv-Muskel-Präparat des Grasfrosches zeigt nach einem Kälteschock wie erwähnt ein paradoxes Ansteigen der Hitzeresistenz; auch die Hitzeadaptation verlief im Gegensatz zur Kälteanpassung paradox. Schlieper (1966b und mündliche Mitteilung) fand bei isolierten Miesmuschelkiemen, daß kurze Hitze- und Kälteschocks von einigen Minuten die Hitze- und Kälteresistenz steigerten, ebenfalls Schocks durch $\mathrm{O}_{2}$-Mangel. Die Kälteund Hitzeadaptation nach längerer Anpassung an normale Temperatur verlief dagegen auch bei diesen Tieren sinnvoll gegenüber beiden Grenztemperaturen. Es mag nicht überraschend sein, daß man im Gegensatz zu intakten Organismen die Schockanpassung an isolierten Geweben nachweisen kann, da diese durchweg resistenter gegenüber extremen Temperaturen sind, so daß auch extreme Schocks angewandt werden können (JANkowsKY 1967b). Mytilus edulis ist insofern ein recht günstiges Versuchsobjekt, als es auch in der Natur extremen Temperaturschwankungen ausgesetzt sein kann, besonders wenn die Muscheln zur Ebbezeit trocken liegen.

Der vorübergehende Charakter der Schockanpassung würde sich zeigen, wenn man die Tiere bei den extremen Temperaturen belassen könnte und die Resistenzänderung nach einiger Zeit zurückginge, doch können Schäden schwer ausgeschlossen werden. Bei der Abbildung 12 in der Arbeit von SCHLIEPER (1966b) mag der Rückgang der Resistenz der Mytilus-Kieme andere Gründe haben, da es sich um Temperaturen des normalen Bereichs handelt. Selbst wenn die Resistenz der Blätter von Campanula persifolia zunächst zunimmt, so fragt es sich, wie lange diese Erhöhung dauert.

Unseres Erachtens ist das hardening im Gegensatz zur Resistenzadaptation im wesentlichen als eine Anpassung an einen stress aufzufassen, die nach den Untersuchungen von SELYE einen vorübergehenden Charakter hat; bei Dauerbelastung versagt die Anpassung im allgemeinen schließlich (über Fische vgl. WEATHERLY 1963). Danach läge also kein besonderes Problem der Temperaturadaptation vor, da auch andersartige Belastungen ähnliche Wirkungen (auch auf die Resistenz gegenüber extremen Temperaturen) haben.

\section{Bleibende Phänomene}

\section{Resistenzadaptationen (Hitze- und Kälteadaptation), sinnvoll oder paradox}

Etliche hierher gehörende Probleme sind schon im vorigen Kapitel behandelt worden. Die Widerstandsfähigkeit gegenüber extremen Temperaturen ändert sich bei 
der bei vielen Tieren vorkommenden Resistenzadaptation nach einem Wechsel der AT in einer bestimmten Zeit (oft in einigen Tagen), um dann für eine lange Zeit konstant zu bleiben, bis die AT erneut verändert wird. Es handelt sich um langfristige Anpassungen wie bei der Leistungsadaptation.

Von der Hitzeadaptation kann man eine Anpassung an extrem tiefe Temperaturen unterscheiden, die wir als Kälteadaptation bezeichnet haben, die man aber mit SCHLIEPER (1966) auch in eine Adaptation der Kälte- und Gefrierresistenz unterteilen kann.

Eine sinnvolle Adaptation an beide Extremtemperaturen findet sich, wie erwähnt, schon bei Ciliaten (Vogel 1966, PolJanskx \& Sukryanoya 1964), ferner bei Krebsen, Fischen etc. Eine Resistenzadaptation läßt sich auch an isolierten Organfunktionen und Zellstoffwechselprozessen nachweisen (PRECHT 1964d, PRECHT \& Christorhersen 1965, Lagerspetz \& Dubitscher 1966, Schlieper 1966 und andere), doch scheint sie bei diesen oft zu fehlen (Ushakov 1964). Sogar psychische Phänomene können eine Kälteadaptation zeigen (Roots \& Prosser 1962). Nach Prosser \& FaHri (1965) läßt sich bei Goldfischen die minimale Dressurtemperatur durch eine Erniedrigung der AT etwa binnen 7 bis 72 Std. herabsetzen.

THIEDE (1965) hat bei seinen Umadaptationsversuchen mit Schwertträgern (Xiphophorus belleri) auch die Hitze- und Kälteresistenz miterfaßt. Als Maß für die Hitzeresistenz diente wie bei den früheren Versuchen der sogenannte Letalindex, das ist das Mittel aus den für Einzelfunktionen gemessenen Grenztemperaturen (Unregelmäßigwerden der Kiemendeckelbewegungen, Aufhören der Brustflossenbewegungen, Kiemendeckelstillstand, Stillstand der Kiemenbewegungen, Aufhören der Herzkontraktionen). Diese Funktionen weisen eine in der genannten Reihenfolge zunehmende Hitzeresistenz auf. Als Maß für die Kälteresistenz diente entweder die Temperatur des Erlöschens der Kiemendeckelbewegungen oder diejenige, welche beim Abkühlen gerade erreicht werden mußte, damit sich die Fische - in $19^{\circ} \mathrm{C}$ zurückgebracht - in einem Tage nicht wieder erholten (Temperaturänderung wie bei den auf p. 377 geschilderten Versuchen).

Diese Grenztemperatur für die Wiederbelebung stieg bei einer Umadaptation von $19^{\circ}$ auf $31^{\circ} \mathrm{C}$ zunächst ziemlich linear an. Die Umadaptation war etwa $z u$ demselben Zeitpunkt beendet wie die anders verlaufende bei der Messung des Erlöschens der Kiemendeckelbewegungen (Abb, 5a). Bei der umgekehrten Umadaptation $\left(31^{\circ} \rightarrow 1^{\circ} \mathrm{C}\right)$ liegt die Grenztemperatur für das Wiederbeleben beim Kältetest bereits am 9. Tag in der Nähe des Kontrollwertes für die $19^{\circ}$-Tiere $\left(2,5^{\circ} \mathrm{C}\right)$. Das Erlöschen der Kiemendeckelbewegungen findet um diese Zeit noch $1^{0}$ über dem Kontrollwert statt; dieser wird erst am 18. Tage erreicht. Der untere Teil der Kurve in Abbildung 2 kann als Kältenarkosebereich bezeichnet werden, weil die Fische in ihm nicht mehr auf mechanische Reize reagieren. Er beginnt bei den $19^{\circ}$-Fischen bei 13 bis $12^{\circ} \mathrm{C}$, bei den $31^{\circ}$-Tieren bei 16 bis $15^{\circ} \mathrm{C}$. Auch diesen sich besonders verhaltenden Bereich könnte man als Maß für die Kälteresistenz verwenden.

Abbildung 5b gibt die zeitliche Änderung der Hitzeletalindizes wieder. Die Umadaptation bei einer Erhöhung der AT von $19^{\circ}$ auf $31^{\circ} \mathrm{C}$ verläuft zunächst rasch und wird dann immer langsamer (Dauer etwa 13 Tage). Eine Umadaptation von $25^{\circ}$ auf $31^{\circ} \mathrm{C}$ ist nach 7 Tagen beendet. Uberführt man die $31^{\circ}$-Fische in $19^{\circ} \mathrm{C}$, so verändert 
sich der Hitzeletalindex nach einem Tage durchschnittlich um $0,5^{\circ} \mathrm{C}$ (er beträgt 41,2 $\pm 0,17^{\circ}$ bei den $31^{0}$-Fischen, $38,8 \pm 0,26^{\circ}$ bei den 190-Tieren). Am 2. Tag ist der Index auf $40,3^{\circ} \mathrm{C}$ gefallen, um dann am 18 . Tag in kleinen Raten den Wert von $38,8^{\circ} \mathrm{C}$ zu erreichen.

Bei den von mehreren Autoren durchgeführten Umadaptationsversuchen sind zwei verschiedene Kurventypen erhalten worden. In einigen Fällen steigert sich die Resistenz gegenüber extremen Temperaturen bei einer Änderung der A'T nach einer mehr
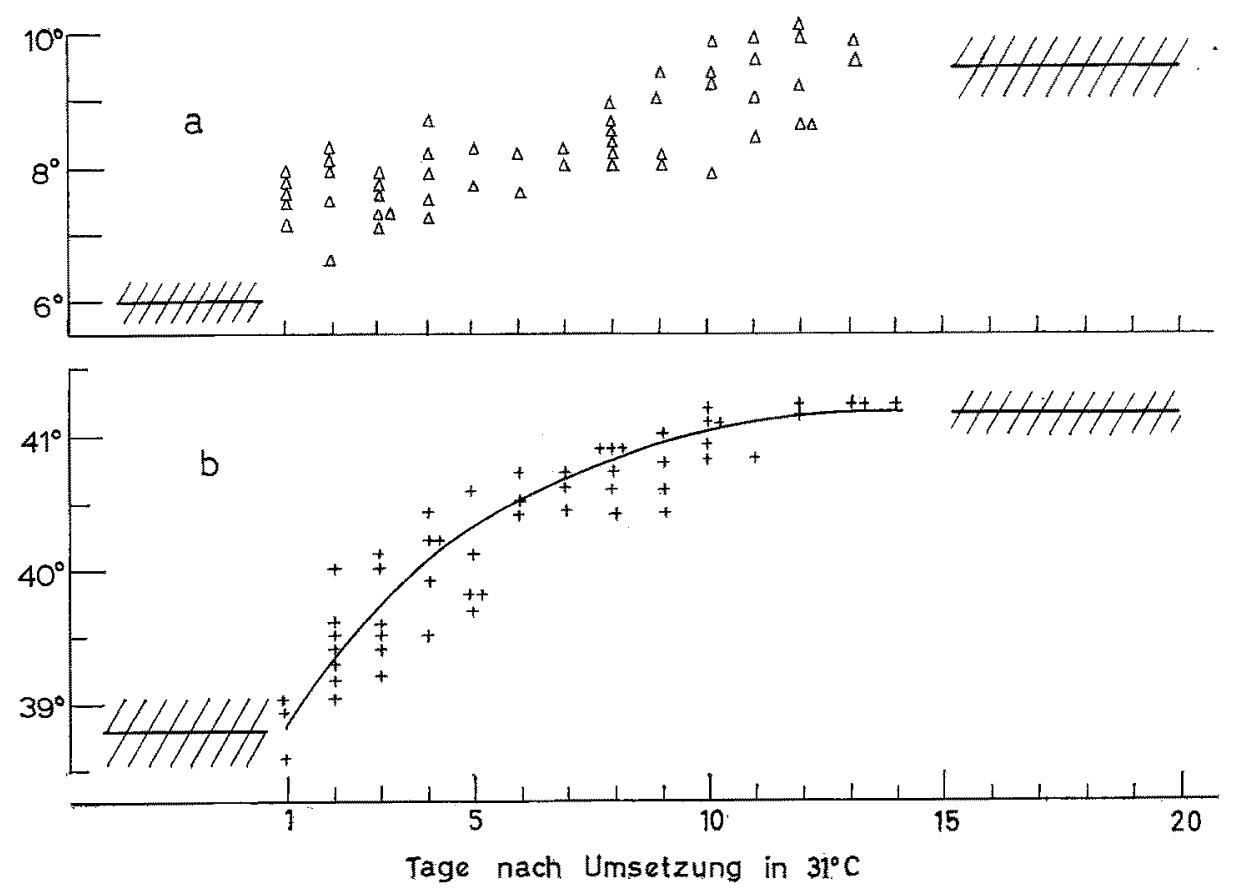

Abb. 5: Umadaptationsversuche an 웅 von Xiphophorus belleri (AT: $19^{\circ} \rightarrow 31^{\circ} \mathrm{C}$, Resistenzadaptation). Die Dreiecke oder Kreuze entsprechen je einem Versuchstier. Schraffierte Linien: volladaptierte Tiere. Abszissen: Tage nach der Umsetzung in $31^{\circ} \mathrm{C}$. (a) Verlauf der „Kiemendeckelstillstandstemperaturen" (Kälteresistenz), Ordinate: Temperatur des Stillstands. (b) Verlauf der "Hitzeletalindizes" (Hitzeresistenz), Ordinate: Temperatur der Indizes

oder weniger langen Latenzzeit; man erhält Sigmoidkurven wie zum Beispiel für den Goldfisch oder den amerikanischen Hummer (BRetT 1944, 1946, McLeese 1956). In anderen Fällen ist die Latenzzeit sehr kurz, wie bei Xiphophorus, oder fehlt ganz. Die Anderung der Resistenz erfolgt zunächst rasch, um dann sukzessive bis zur vollständigen Angleichung abzunehmen (logarithmische Funktionen der Zeit). Diese Kurvenform fanden zum Beispiel Doudoroff (1942) für Girella, 'Tsukuda (1960b) für Lebistes und Hutchison (1961) für Urodelen. Tsukuda glaubt, daß die Untersuchungsmethode für den Verlauf der Kurven entscheidend ist.

Wie bei der Leistungsadaptation ist der Vorgang der Anpassung an extreme Temperaturen oft selbst temperaturabhängig. Dieses zeigte sich auch bei den Versuchen von 
THIEDDE (1965) mit Schwertträgern, jedoch kaum bei denen von Vogel (1966) mit Zoothamnium biketes. Bei einer bestehenden Temperaturabhängigkeit nimmt die Adaptation nach einer Senkung der AT längere Zeit in Anspruch als nach einer erneuten Erhöhung der AT auf den ursprünglichen Wert. Nach BRETT (1946) dauert die Anpassung bei Uberführung der Goldfische von 4 in $12^{\circ}$ : 20 Tage, von 12 in $20^{\circ}$ : 7 Tage und von 20 in $28^{\circ}: 3$ bis 4 Tage $\left(Q_{10} \approx 3\right)$. In manchen Fällen soll eine sehr starke Temperaturabhängigkeit bestehen (vgl. SPOoR 1955, DickIE 1958).

Bei hohen Vorbehandlungstemperaturen kann die Anpassungsgeschwindigkeit wieder abnehmen; dies war nach Doudoroff (1942) bei dem Fisch Girella bei $26^{\circ} \mathrm{C}$ der Fall. So verlief die Kälteadaptation bei einem Wechsel der AT von 20 auf $26^{\circ}$ langsamer als die bei der Rückführung in $20^{\circ} \mathrm{C}$. Bei Lebistes reticulatus (AT: $18^{\circ}, 2^{\circ}$, $28^{\circ} \mathrm{C}$ ) nahm bei allen möglichen Umadaptationen die Anpassung an die mittlere AT die kürzeste Zeit in Anspruch, und zwar bei der Kälte- und auch Hitzeanpassung (T'sukuda 1960). Die Abhängigkeitskurven der Adaptation von der Temperatur weisen somit auch beim Guppy ein Maximum auf.

Es ist untersucht worden, ob man bei raschen und starken Senkungen der AT eine Anpassung dadurch verhindern kann, daß man den Regulationsmechanismus durch tiefe Temperaturen ausschaltet. Dies scheint nad Mellanby $(1939,1959)$ bei der Kälteadaptation von Insekten vorzukommen, doch gilt dies für andere Fälle nicht (vgl. Losina-Losinsky, Sakar, Tumanov 1964). Nach Payne (1927) soll bei Larven von Synchroa punctata die Kälteresistenz durch einen Aufenthalt bei - $3^{\circ} \mathrm{C}$ noch zunehmen.

Bei den Organismen, die wie mehrere Winterpflanzen eine Resistenzadaptation aufweisen, die nur in bezug auf die eine Extremtemperatur sinnvoll verläuf, gegenüber der anderen jedoch paradox, ist es möglich, daß ein Mechanismus dafür verantwortlich ist und die allgemeine Resistenz gegenüber vielerlei Faktoren bestimmt, einschließlich der beiden Extremtemperaturen. Viele der bisher für die Resistenz verantwortlich gemachten Faktoren (wie z. B. Änderungen des Wassergehaltes, Vermehrung des gebundenen Wassers auf Kosten des freien, die Bildung von Schutzstoffen oder von besonderen Bindungen in den Molekülen) verändern die Widerstandsfähigkeit gegenüber beiden Extremtemperaturen in der gleichen Richtung. Es spricht jedoch gegen die Wirkung eines einzigen Regulationsmechanismus, wenn der zeitliche Verlauf der Resistenzänderung bei den Umadaptationsversuchen für die verschiedenen Umweltfaktoren (Sauerstoffmangel, Gifte etc.) unterschiedlich ist.

Eine sinnvolle Anpassung an beide Extremtemperaturen dürfte im allgemeinen nicht durch einen Mechanismus gesteuert werden, obwohl dies (rein theoretisch betrachtet) möglich wäre, selbst wenn, was bei höheren Tieren oft zu erwarten ist, nicht dieselbe Organfunktion die Hitze- und Kälteresistenz des Tieres bestimmt. Es könnten nämlich übergeordnete Faktoren verantwortlich sein. HOAR (in GORBMAN 1959) ist früher zum Beispiel von der Arbeitshypothese ausgegangen, daß das Schilddrüsenhormon die Kälteresistenz erhöht, die Hitzeresistenz aber herabsetzt. Wenn die Hormonproduktion mit fallender AT ansteigen würde, so wäre die sinnvolle Anpassung an beide Extremtemperaturen verständlich, vielleicht sogar zusätzlich eine Leistungsadaptation im Sinne einer Kompensation, wenn man unterstellt, daß das Schilddrüsenhormon auch bei den wechselwarmen Wirbeltieren den Stoffwechsel stimuliert; hier soll 
nicht auf das Für und Wider eingegangen werden (vgl. PRECHT 1964d, THIEDE 1965, KLICKA 1965). Auch manche lonen können eine entgegengesetzte Wirkung auf die Hitze und Kälteresistenz von Zellen haben (vgl. Henckel \& Badanova 1956, ScotT \& STrong 1964).

$\mathrm{Zu}$ dieser Problematik können Untersuchungen über den zeitlichen Verlauf bei Umadaptationen beitragen. VoGEL (1966) wies für Zoothamnium biketes (mit sinnvoller Anpassung an beide Extremtemperaturen) nach, daß eine Erhöhung des Magnesiumgehaltes im Meerwasser die Hitzetoleranz erhöht, nicht aber die Kälteresistenz. Schon bei diesem Einzeller ist also beides unabhängig voneinander. $\mathrm{Da} B$ auch nicht ein übergeordneter Mechanismus beides gleichzeitig im Sinne einer sinnvollen Hitze- und Kälteadaptation beeinflußt, zeigte sich daran, daß bei Umadaptationsversuchen der Gewinn (Verlust) an Hitzeresistenz nicht dem Verlust (Gewinn) an Kältewiderstands-fähigkeit zeitlich parallel verläuft. Bei entsprechenden Versuchen von THIEDE mit Schwertträgern war die Übereinstimmung (besonders hinsichtlich der Zeitdauer) größer, doch auch nicht exakt genug, um daraus weitere Schlüsse zu ziehen (vgl. auch die Abb. 1 und 2 von Tsukuda 1960b, ferner Brett 1946). Nach Tsukuda (1960c) waren die individuellen Schwankungen der Hitze- und Kälteresistenz beim Guppy nicht korreliert. Nach Doudoroff (1942) beträgt der Unterschied der „lower median tolerance limits" von Girella, die an $20^{\circ} \mathrm{C}$ beziehungsweise $28^{\circ} \mathrm{C}$ angepaßt waren, etwa $4,3^{\circ} \mathrm{C}$, die "upper median tolerance limits" unterscheiden sich jedoch nicht. Auf diesbezügliche Befunde von BASEDow wurde schon hingewiesen (p. 387).

Man kann natürlich auch den zeitlichen Verlauf der Leistungsadaptation mit dem der Resistenzadaptation vergleichen. Auch hier ist zu berücksichtigen, daß die Leistungsadaptation jeder Organfunktion unterschiedlich verlaufen kann (vgl. PRECHT 1964d). Nadh LAgerspetz \& Dubitscher (1966) dauert die Leistungsadaptation bei einer Uberführung der Muschel Anodonta cygnea cellensis von $5^{\circ}$ in $21^{\circ} \mathrm{C} 7$ bis 8 Wodhen (gemessen an der Cilienaktivität der Kiemen); deren Hitzeresistenzänderung benötigte aber nur 4 Tage für die gleiche Umadaptation.

Der Vorgang der Resistenzadaptation nach einem Wechsel der AT nimmt meist einige Tage oder eine noch längere Zeit in Anspruch. Einige Autoren fanden aber auch kürzere Anpassungszeiten bei Tieren, und zwar von 20 bis 24 Std. (nach Schlieper 1966 bei Tentakelstücken von Metridium senile, nach MELIANBy 1939, 1954, 1959 und FreE \& SPENCER-BOOTH 1960 bei Insekten, nach BRAtTSTROM \& LAWRENCE 1.962 und Hutchrson 1961 bei Amphibien, nach Sumner. \& Doudoroff 1938 bei Gillichthys mirabilis, nach Doudoroff 1942 bei Girella nigricans und nach BRETT 1944 bei Ameiurus nebulosus; vgl. ferner LoEb \& Wasteneys 1912, LackNitzkaja 1963). Bei der Leistungsadaptation (speziell bei den Nacheffekten) spielen sicherlich Eiweißsynthesen eine große Rolle. Es ist damit zu rechnen, daß Proteinsynthesen auch für die Resistenzadaptation Bedeutung haben. Kürzere Anpassungszeiten sprechen nicht unbedingt gegen das Mitwirken synthetischer Prozesse, da diese unter Umständen sehr schnell ablaufen können (vgl. LANG \& SeKERIs 1964). Bei sehr kurzen Adaptationszeiten ist aber in jedem Fall zu prüfen, ob nicht andere Phänomene wie das hardening miterfaßt worden sind.

Obwohl die obere Grenztemperatur bei den Versuchen von Sumner \& Doudorofr (1938) schon nach etwa einem Tage im wesentlichen abgeschlossen ist, wenn die Tiere 
von $20^{\circ}$ in $30^{\circ} \mathrm{C}$ überführt worden sind, dauert die Rückadaptation mehr als 23 Tage, wenn die Fische sich 46 Tage bei $30^{\circ} \mathrm{C}$ aufhielten, und nur 30 Tage, wenn sie sich dort nur für 3 Tage anpassen konnten. Es findet somit eine Verankerung des Adaptationseffektes statt, ohne daß dies an der Grenztemperatur sichtbar wird. Nach MeLLANBY (1939) verläuft dagegen die Kälteadaptation von Bettwanzen, die während mehrerer Generationen bei $30^{\circ} \mathrm{C}$ lebten, an $15^{\circ} \mathrm{C}$ genauso schnell wie bei den Tieren, die erst einen Tag bei $30^{\circ} \mathrm{C}$ zugebracht hatten.

Anhangweise sei hier ein auch für die Entwicklungsprozesse geltendes Problem erörtert. Bei den bisher beschriebenen Versuchen sind konstante Vorbehandlungstemperaturen angewandt worden. In der Natur unterliegen die Tiere jedoch einem mehr oder weniger starken Tag-Nacht-Wechsel der Temperatur, den man auch im Versuch nachahmen kann. Derartige Untersuchungen mit tagesperiodisch schwankenden Temperaturen hat man des öfteren an sich ändernden Reaktionssystemen durchgeführt. In manchen Fällen unterscheiden sich die Entwicklungszeiten nicht, wenn man konstante oder alternierende Temperaturen mit gleichen Mitteln anwandte, in anderen Fällen wirkte sich der Wechsel im Sinne einer Anderung der Entwicklungsgeschwindigkeit (zumeist Beschleunigung) aus. GRAINGER (1959) macht hierfür verschiedene Faktoren verantwortlich. "Firstly, the rate of subsequent development may be affected (after-effects)... Secondly, development rate may be affected during the time that the temperature is altering (immediate-effects)." Diesen Effekt konnte GraInger bei der Entwicklung des Grasfrosches nachweisen, allerdings nur für die Gastrulation. Schwankende Temperaturen erzeugten während dieser Zeit eine ausgesprochene Verzögerung der Entwicklungsgeschwindigkeit. KHAN (1965) erhielt bei Acanthocyclops viridis dagegen Entwicklungsbeschleunigungen, und zwar wiederum nur für bestimmte Stadien.

Ein immediate-effect kann schon durch folgenden, zuerst von KAUFMANN (1932) erwähnten Tatbestand zustandekommen: Liegt der Temperaturabhängigkeit eine exponentielle Abhängigkeit zugrunde, so muß sich jede Abweichung von konstanten Temperaturbedingungen im Optimum als eine Entwidklungshemmung auswirken, ganz gleich, ob sie nach oben oder unten erfolgt. Bei den Kurvenpunkten der ansteigenden Schenkel kann sich eine Temperaturschwankung in einer noch größeren Beschleunigung oder Verzögerung der Entwicklung ausdrücken. GRAINGER und KHAN berücksichtigen diese rein mathematischen Gesichtspunkte.

Bei der Untersuchung sich nicht ändernder Reaktionssysteme hat man weit seltener tagesperiodisch schwankende T'emperaturen während der Vorbehandlung angewandt. Berkholz (1966) hat kürzlich derartige Versuche mit Idus idus durchgeführt, also einem Fisch, der hinsichtlich vieler Lebensprozesse eine ausgesprochene Leistungs- und auch Resistenzadaptation aufweist. Wenn beide Anpassungen selbst temperaturabhängig sind, so muß dies, rein theoretisch betrachtet, folgende Konsequenzen haben: Da die Anpassung bei höheren Temperaturen rascher verläuft als bei tieferen, müssen sich die Meßpunkte der inkonstant vorbehandelten Tiere den Werten nähern, die man für konstant vorbehandelte warmadaptierte Tiere erhält. Andererseits muß man den zeitlichen Verlauf der Leistungs- und Resistenzadaptation bei konstant vorbehandelten Tieren berücksichtigen. Nimmt die anfangs schnell erfolgende Umadaptation immer mehr an Geschwindigkeit ab (logarithmische Funktion der Zeit), das heißt, ist die Geschwindigkeit davon abhängig, inwieweit der Endwert bereits erreicht ist, so muß dies bei der 
inkonstanten Vorbehandlung dem ersten Effekt immer mehr entgegenwirken, so daß schließlich bei einem nach der Seite der warmadaptierten Tiere hin verlagerten Wert ein Endzustand der Adaptation erreicht wird. BERKHoLz (1966) hielt die Nerflinge bei $15^{\circ}$ und $22^{\circ} \mathrm{C}$ und bei 12 stïndig zwischen $15^{\circ}$ und $22^{\circ} \mathrm{C}$ schwankenden Vorbehandlungstemperaturen. Die Meßwerte für die inkonstant vorbehandelten Fische näherten sich denen der $22^{\circ}$-Tiere (merklich beim Sauerstoffverbrauch des isolierten Muskelgewebes, sehr deutlich bei der Hitzeresistenz der Fische und kaum bei der Hitzeresistenz des Sauerstoffverbrauchs des Muskelgewebes). Biologisch betrachtet ist dieser Effekt am wichtigsten für die Hitzeresistenz der intakten Tiere, da diese gleichwohl gefährdet sind, ob sie nun für den ganzen oder einen halben Tag den hohen Temperaturen ausgesetzt sind. Ahnliche Resistenzverschiebungen nach inkonstanter Vorbehandlung fanden HEATH (1963) bei Forellen und EDNEY (1964) bei Isopoden. Nach HEATH suchen die Fische tagesperiodisch verschiedene Temperaturen auf, zeitweise sogar sehr hohe. Dadurch wird ihre Resistenz gesteigert, in einer Versuchsserie sogar mehr, als dies bei konstanter Vorbehandlung möglich war.

Die Kälteresistenz von Fischen aus wechselnden Temperaturen kann erwartungsgemäß geringer sein als die von Tieren aus einer mittleren AT (SUMNER \& DOUDOROFF 1938). Der Befund von EDNEx (1964), daß Asseln, die einer periodisch wechselnden Temperatur $\left(10 \longleftrightarrow 30^{\circ}\right)$ ausgesetzt wurden, so hitzeresistent wie $30^{\circ}$-Tiere und so kälteresistent wie $20^{\circ}$-Tiere sind, spricht auch für einen unterschiedlichen Mechanismus bei der sinnvollen Anpassung an beide Extremtemperaturen. KrRBERGER (1953) erhielt für den Sauerstoffverbrauch von Lumbriculus variegatus mittlere Werte nach inkonstanter Vorbehandlung.

\section{Lang dauernde Nacbwirkungen}

SMITH $(1956,1957)$ unterscheidet bei der Zunahme der Hitzeresistenz von Drosophila subobscura mit steigender AT eine "longlasting developmental acclimatization during preadult life, and a transitory physiological acclimatization in adults". Die während der Jugendzeit einwirkende AT kann Nachwirkungen für das ganze Leben haben. Bei Guppys hatte darüber hinaus die AT einen Einfluß, bei der die Elterngeneration gehalten wurde (TsukUDA 1960a).

Einen Übergang stellen Fälle einer ungewöhnlich langen Nachwirkung bei adulten Tieren dar. Nach einer Erhöhung der AT für 2 bis 3 Tage beobachteten Sumner \& DOUDOROFF (1938) eine erhöhte Hitzeresistenz ihrer Fische während eines Monats (vgl. Loeb \& WASTENEYS 1912, Dickie 1958).

\section{ZUSAMMENFASSUNG}

1. Die Reaktionen und Adaptationen nach einer Anderung der Adaptationstemperatur haben wir abzugrenzen versucht und ihren zeitlichen Verlauf geschildert. Eigene Untersuchungen wurden als Beispiele eingefügt.

2. Bei Silberorfen (Idus idus) hält der Abfall der Frequenz der Kiemendeckelbewegungen für eine längere Zeit an, wenn man die Vorbehandlungstemperatur senkt. 
3. Bei 우 des Schwertträgers (Xipbophorus helleri) ist bei mehreren Versuchstemperaturen der zeitliche Verlauf einer Umadaptation am Beispiel der Kiemendeckelbewegungen verfolgt worden. Dieser Prozeß ist selbst temperaturabhängig und läuft für die verschiedenen Bereiche der Versuchstemperatur unterschiedlich schnell ab.

4. Die Meßwerte für die Hitzeresistenz von Goldorfen (Idus idus) hängen von der Geschwindigkeit der Temperaturerhöhung ab.

5. Das Phänomen eines "hardening" im Sinne von Alexandrov (1964) konnte bei den Fischen Idus idus, Anguilla vulgaris, Xiphophorus belleri und bei dem Ciliaten Zoothamnium biketes nicht einwandfrei von einer Resistenzadaptation abgegrenzt werden.

6. Nach einem Wechsel der Adaptationstemperatur wurden die schnell verlaufenden Anderungen der Kälteresistenz des Cilienepithels auf den Fühlerspitzen der Schnecke Planorbis corneus (auch an isolierten Fühlern) gemessen.

7. Ferner wurden bei $q q$ von Xiphophorus helleri die Änderungen der Kälteresistenz hinsichtlich des Stillstandes der Kiemendeckel sowie Anderungen der Hitzeletalindizes untersucht.

Diese Untersuchung wurde mit Apparaten durchgeführt, welche die Deutsche Forschungsgemeinschaft $H$. PRECHT zur Verfügung stellte.

\section{ZITIERTE LITERATUR}

Alexandrov, V. Y., 1964. Cytophysiological and cytoecological investigations of resistance of plant cells towards the action of high and low temperature. Q. Rev. Biol. 39, 35 77.

Ata, S. \& STAIB, F., 1957. Kälteeinfluß auf Hefen und hefeartige Pilze. Zentbl. Bakt. Parasitkde (Abt. 2) 110, 659-673.

BALDWIN, W. F., 1954. Acclimation and lethal high temperatures for a parasitic insect. Can. J. Zool. 32, 157-171.

BAsU, S. P., 1959. Active respiration of fish in relation to ambient concentrations of oxygen and carbon dioxyd. J. Fish. Res. Bd Can. 16, 175-212.

Behmann, F. W. \& MeIssner, H. D., 1964. Untersuchungen zur Frage der Temperaturadaptation an einem chemisdren Zellmodell. Helgoländer wiss. Meeresunters. 9, 371-379.

Benex, J., 1961. La survie d'explants de Planorbes (Australorbis glabratus) en milieu synthétique, antiseptique et nutritif. C. $r$. hebd. Séanc. Acad. Sci., Paris 253, 734-736.

BENTHE, H.-F., 1954. Uber die Temperaturabhängigkeit neuromuskulärer Vorgänge. $Z$. vergl. Physiol. 36, 327-351.

Berkholz, G., 1966. Uber die Temperaturadaptation des Nerflings (Idus idus L., Pisces) nach inkonstanter Vorbehandlung. Z. wiss. Zool. 174, 377-399.

Bishat, H. M., 1965. Resistance of Tilapia nilotica L. to high temperatures. Hydrobiologia 25, 473-488.

Boycott, B. B., Gray, E. G. \& Gutllery, R. W., 1961. Synaptic structure and its alteration with environmental temperature: a study by light and electron microscopy of the central nervous system of lizards. Proc. $R$. Soc. 154, 151-172.

BratTSTROM, B. H., 1963. A preliminary review of the thermal requirements of amphibians. Ecology 44, 238-255.

- \& LAWRENCE, P., 1962. The rate of thermal acclimation in anuran amphibians. Physiol. Zool. 35, 148-156. 
BrETT, J. R., 1944. Some lethal temperature relations of Algonquin fishes. Publs. Ont. Fish. Res. Lab. 63, 1-49.

- 1946. Rate and gain of heat-tolerance in goldfish. Publs. Ont. Fish. Res. Lab. 64, 9-28.

- 1956. Some principles in the thermal requirements of fishes. Q. Rev. Biol. 31, 75-87.

BUDDENBROCK, E. v., 1960. Über die Temperaturabhängigkeit der Narkosewirkung bei wechselwarmen Tieren. Z. wiss, Zool. 164, 173-187.

Bünning, E., 1963. Die physiologische Uhr. 2. Aufl. Springer, Berlin, 153 pp.

CHRISTOPHERSEN, J., 1963. Untersuchungen über den Einfluß der Adaptationstemperatur auf die Hitzeresistenz und Aktivität der Hexokinase von Hefezellen. Arch. Mikrobiol, 45, 58-64.

- 1967. Adaptive temperature responses of microorganisms (im Druck).

- \& P PECHT, H., 1950a. Untersuchungen über die Temperaturabhängigkeit von Lebensprozessen bei Hefen. Biol. Zbl. 69, 300-323.

- - 1950b. Fermentative Temperaturadaptation. Biol. Zbl. 69, 240-256.

- - 1952. Untersuchungen zum Problem der Hitzeresistenz. I. Versuche an Karauschen (Carassius vulgaris Nrs.). Biol. Zbl. 71, 313-326.

- - 1956. Uber die Kälteresistenz der Hefe Tornlopsis kefyr. Biol. Zbl. 75, 689-705.

Dickie, L. M., 1958. Effects of high temperature on survival of the giant scallop. J. Fish. Res. Bd Can. 15, 1189-1211.

Doudoroff, P., 1942. The resistance and acclimatization of marine fishes to temperature changes. 1. Experiments with Girella nigricans. Biol. Bull. mar. biol. Lab., Woods Hole 83, 213-244.

- 1945. The resistance and acclimatization of marine fishes to temperature changes. 2. Experiments with Fundulus and Atberinops. Biol. Bull. mar. biol. Lab., Woods Hole 88, 194-206.

EDNEY, E. B., 1964. Acclimation to temperature in terrestrial isopods. 1. 2. Physiol. Zool. 37, $364-377,378-394$.

ERBERG, D. R., 1958. Respiration in tissue of goldfish adapted to high and low temperatures. Biol. Bull, mar, biol. Lab., Woods Hole 114, 308-316.

Esch, H., 1960. Uber die Körpertemperaturen und den Wärmehaushalt von Apis mellifica. Z. vergl. Physiol. 43, 305-335.

Evans, R. M., Purdie, F. C. \& Hrckman, C. P., jr., 1962. The effect of temperature and photoperiod on the respiratory metabolism of the rainbow trout (Salmo gairdneri). Can. J. Zool. 40, 107-118.

FreE, J. B. \& Spencer-Boothe, Y., 1960. Chill-coma and cold death temperatures of Apis mellifera. Entomologia exp. appl. 3, 222-230.

FrEEMAN, J. A., 1950. Oxygen consumption, brain, metabolism and respiratory movements of goldfish during temperature acclimatization, with special reference towards lowered temperatures. Biol. Bull. mar. biol. Lab., Woods Hole 99, 416-424.

FRY, F. E. J., HAR'T, J. S. \& WALKER, K. F., 1946. Lethal temperature relations for a sample of young speckled trout, Salvelinus fontinalis. Publs. Ont. Fish. Lab. 66, 8-35.

Gorbman, A. (Ed.), 1959. Comparative endocrinology. Wiley, New York, $746 \mathrm{pp}$.

Gosh, A. \& CHANCE, B., 1964. Oscillations of glycolytic intermediates in yeast cells. Biochem. biophys. Res. Commun. 16, 174-181.

GRAINGER, J. N. R., 1959. The effects of constant and varying temperatures on the developing eggs of Rana temporaria. Zool. Anz. 163, 267-277.

- 1960. The early phases in the adjustment of respiratory rates of unicellular organisms to new temperatures and the simulation of these in a model. Z. wiss. Zool. 163, 317-341.

HEAT resistance of cells of animals, 1965. In: Collected articles. Inst. Cytol., Acad. Sci. USSR 8 [Russ.].

HeAtH, W. G., 1963. Thermoperiodism in sea-run cutthroat trout (Salmo clarki clarki). Science N. Y. 142, 486-488.

Heatwole, H., Mrrcado, N. \& Ortiz, E., 1965. Comparison of critical thermal maxima of two species of Puerto Rican frogs of the genus Eleutherodactylus. Physiol. Zool. 38, 1-8.

HENCKEL, P. A. \& BADANOVA, K. A., 1956. Investigation of protoplasmic viscosity and the resistance of plants to high and low temperatures. Fiziologiya Rast. 3, 455-462. 
Heusner, A. \& Stussr, T., 1964. Métabolisme énergétique de l'abeille isolée: son rôle dans la thermorégulation de l'abeille de la ruche. Insectes soc. 11, 239-266.

HOAR, W. S. \& ROBERTSON, G. B., 1959. Temperature resistance of goldfish maintained under controlled photoperiod. Can. J. Zool. 37, 419-428.

HochachKa, P. W. \& HAYEs, F. R., 1962. The effect of temperature acclimation on pathways of glucose metabolism in the trout. Can. J. Zool. 40, 261-270.

Hofrmann, K., 1957. Uber den Einfluß der Temperatur auf die Tagesperiodizität bei einem Poikilothermen. Naturwissenschaften 44, 358.

House, H. L., Riordan, D. F. \& Barlow, J. S., 1958. Effects of thermal conditioning and of degree of saturation of dietary lipids on resistance of an insect to a high temperature. Can. J. Zool. 36, 629-632.

Hutchison, V. H., 1961. Critical thermal maxima in salamanders. Physiol. Zool. 34, 92-125.

INGRAM, J. L., 1962. Temperature relations. In: The bacteria. A treatise on structure and function. Ed. by I. C. Gunsalus \& R. Y. Stanier. Vol. 4. Physiology of growth. New York, Acad. pr., 265-296.

JANKOWSKY, H.-D., 1964. Der Einfluß des Blutes auf den Sauerstoffverbrauch des isolierten Muskelgewebes von Schleien (Tinca tinca L.). Zool. Anz. 172, 233-239.

- 1967a. Der Einfluß der Temperatur auf die Sonnenkompaßorientierung bei Talitriden (im Druck).

- 1967b. Untersuchungen über die partikuläre saure Phosphatase bei Tubificiden. Zool. $\mathrm{Jb}$. Physiol. (im Druck).

- \& KorN, H., 1965. Der Einfluß der Adaptationstemperatur auf den Mitochondriengehalt des Fischmuskels. Naturwissenschaften 52, 642-643.

Kasbohm, P., 1967. Der Einfluß des Lichts auf die Temperaturadaptation von Rana temporaria L. Helgoländer wiss. Meeresunters. 16 (im Druck).

Kaufmann, O., 1932. Einige Bemerkungen über den Einfluß von Temperaturschwankungen auf die Entwidklungsdauer und Streuung bei Insekten und seine graphische Darstellung durch Kettenlinie und Hyperbel. Z. Morph. Ökol. Tiere 25, 353-361.

KhAN, F. M., 1965. The effects of constant and varying temperatures on the development of Acanthocyclops viridis (Jurine). Proc. R. Ir. Acad. 64, 117-130.

KINNE, O., 1963. The effects of temperature and salinity on marine and brackish water animals. 1. Temperature. Oceanogr. mar. Biol. A. Rev. 1, 301-340.

- 1964a.... 2. Salinity and temperature salinity combinations. Oceanogr. mar. Biol. A. Rev. 2, 281-339.

- 1964b. Non-genetic adaptation to temperature and salinity. Helgoländer wiss. Meeresunters. 9, 433-458.

- 1965. Physiologische und ökologische Aspekte des Lebens in Astuarien. Helgoländer wiss. Meeresunters. 11, 131-256.

Kirberger, Ch., 1953. Untersuchungen über die Temperaturabhängigkeit von Lebensprozessen bei verschiedenen Wirbellosen. Z. vergl. Physiol. 35, 175-198.

KuICKA, J., 1965. Temperature acclimation in goldfish: lack of evidence for hormonal involvement. Physiol. Zool. 38, 177-189.

Kovaljeva, N. E. \& Selivanova, G. V., 1963. The influence of temperature factor on DNA and RNA contacts in Paramecium caudatum. Tsitologiya 5, 273-278.

KRÜGER, G., 1962. Über die Temperaturadaptation des Bitterlings (Rhodeus amarus BLOCH). Z. wiss. Zool. 167, 87-104.

Lagerspetz, K. Y. H. \& Dubrtscher, I., 1966. Temperature acclimation of ciliary activity in the gills of Anodonta. Comp. Biochem. Physiol, 17, 665-671.

LAKNITSKAYA, A. F., 1963. Effects of the rearing temperature on the thermostability of some algae. Tsitologiya 5, 135-141.

LANG, N. \& SEKERIS, C. E., 1964. Zum Wirkungsmechanismus der Hormone. 3. Einfluß von Cortisol auf den Ribonucleinsäure- und Proteinstoffwechsel in Rattenleber. Hoppe-Seyler's Z. physiol. Chem. 339, 238-248.

LANGE, O., 1961. Die Hitzeresistenz einheimischer immer- und wintergrüner Pflanzen im Jahreslauf. Planta 56, 666-683. 
LevitT, J., 1956. The hardiness of plants. Acad. pr., New York, 278 pp.

LOEB, H. \& WASTENEYS, H., 1912. On the adaptation of fish (Fundulus) to higher temperatures. J. exp. Zool. 12, 543-557.

Love, G. J. \& WHELCHEL, J. G., 1957. Lethal effects of high temperatures on the immature stages of Anopheles quadrimaculatus. Ecology 38,570-576.

Lühmann, M. \& Drees, O., 1952. Über die Temperaturabhängigkeit der Atmung sommerschlafender Blattkäfer. Zool. Anz. 148, 13-22.

Mazur, P., 1961. Manifestation of injury in yeast cells exposed to subzero temperatures. 1, 2. J. Bact. 82, 662-672, 673-684.

MCLEESE, D. W., 1956. Effects of temperatures, salinity and oxygen on the survival of the American lobster. J. Fisb. Res. Bd. Can. 13, 247-272.

Mellanby, K., 1939. Low temperature and insect activity. Proc. R. Soc. 127, 473-487.

- 1954. Acclimation and the thermal deathpoint in insects. Nature, Lond. 173, 582-583.

- 1959a. Life at low temperatures. Advmt. Sci., Lond. 60, 409-417.

- 1959b. Acclimatization affecting the position of cold and heat death points of larvae of Aedes aegypti (L.). Bull. ent. Res. 50, 821-823.

Müller, H. J., 1966. Probleme der Insektendiapause. Zool. Anz. (Suppl. Bd) 29, 192-222.

Nopp, H., 1965. Temperaturbezogene Regulationen des Sauerstoffyerbrauchs und der Herzschlagrate bei einigen Landpulmonaten. Z. vergl. Pbysiol. 50, 641-659.

OHLendusch, H.-D. \& PRECHT, H., 1960. Über den Umkehrpunkt von Atmungskurven bei hohen Temperaturen. 2. Z. wiss, Zool. 164, 364-373.

Okasha, A. Y. K., 1964. Effects of high temperature in Rhodniws prolixus. (Stal.). Nature Lond. 204, 1221-1222.

PAYNe, N. M., 1927. Freezing and survival of insects at low temperatures. J. Morph. 43, 521 to 546.

Pitkow, R. B., 1960. Cold death in the guppy. Biol. Bull. mar. biol. Lab., Woods Hole 119, 231-245.

PRECHT, H., 1959. Untersuchungen über die Resistenzadaptation einiger Organfunktionen von Warmwasserfischen gegenüber extremen Temperaturen. Z. vergl. Physiol. 42, 365-382.

- 1960a. Über die Resistenzadaptation von Organfunktionen des Grasfrosches (Rana temporaria L.) gegenuiber extremen Temperaturen. Z. wiss. Zool. 164, 336-353.

- 1960b. Uber den Umkehrpunkt von Atmungskurven bei hohen Temperaturen. 1. Versuche mit Muskelgewebe des Grasfrosches (Rana temporaria L.). Z. wiss. Zool. 164, 354-363.

- 1961. Temperaturanpassungen bei wechselwarmen Tieren. Zool. Anz. (Suppl. Bd) 24, 38 bis 60 .

- 1962. Uber die Temperaturadaptation des Schwertträgers Xiphophorus helleri HeckeL (Poeciliidae, Pisces). Z. wiss. Zool. 167, 73-86.

- 1963. Anpassungen wechselwarmer Tiere zum Uberleben extremer Temperaturen. Naturw. Rdsch., Stuttg. 16, 9-16.

- 1964a. Gibt es biologische "Langzeituhren“ bei Tieren? Einige Versuche zum Problem der Beendigung yon Diapausen bei Tieren. Zool. Anz. 172, 87-95.

- 1964b. Anpassungen wedhselwarmer Tiere im normalen Temperaturbereich und ihre Ursachen. Naturze. Rdsch., Stuttg. 17, 438-442.

- 1964c. Uber die Bedeutung des Blutes für die Temperaturadaptation von Fischen. Zool. Jb. Physiol. 71, 313-327.

- 1964d. Über die Resistenzadaptation wechselwarmer Tiere an extreme Temperaturen und ihre Ursachen. Helgoländer wiss. Meeresunters. 9, 392-411.

- 1965. Ergänzende Versuche zur Bedeutung des Blutes für die Temperaturadaptation bei Fischen. Zool. Anz, 175, 301-310.

- \& Christophersen, J., 1965. Temperaturadaptation des Cilienepithels isolierter Kiemen und Fühler von Mollusken. Z. wiss. Zool. 173, 197-209.

- - \& Hensed, H., 1955. Temperatur und Leben. Springer, Heidelberg, 514 pp.

- \& Lindner, E., 1966. Reaktionen, Regulationen und Adaptationen der Tiere nach Veränderung der Temperatur und des Salzgehaltes. Versuche mit Zootbamninm biketes PrechT (Ciliata, Peritr.). Helgoländer zeiss. Meeresunters. 13, 354-368. 
PrEChT, I., 1967. Untersuchungen über Diapause, Leistungsadaptation und Temperaturresistenz einiger Insekten und Schnecken. Z. wiss. Zool. (im Druck).

Propper, A., 1965. Différences de sensibilité à la température chez deux variétés de Paramecium caudatum. Archs Zool. exp. gén. 105, 259-271.

Prosser, C. L. (Ed.), 1958. Physiological adaptation. A symposium held ... at the Mar. Biol. Lab., Woods Hole, Mass., Sept. 5-6, 1957. Am. Physiol. Soc., Washington, DC, 185 pp.

- 1962. Acclimation of poikilothermae vertebrates to low temperatures. In: Comparative physiology of temperature regulation. Ed. by J. P. Hannon \& E. Viereck. Arctic Aeromed. Lab., Ft Wainwright, Alaska, 3, 1-44.

- \& FARHI, E., 1965. Effects of temperature on conditioned reflexes and on nerve conduction in fish. Z. vergl. Physiol. 50, 91-101.

Remmert, H., 1965. Biologische Periodik. In: Handbuch der Biologie. Hrsg. von Fritz Gessner. Akad. Verl.Ges. Athenaion, Frankfurt a. M., 5, 335-411.

Roserts, J. L., 1961. The influence of photoperiod upon thermal acclimation by the crucian carp, Carassius carassius L. Zool. Anz. (Suppl. Bd) 24, 73-78.

- 1964. Metabolic responses of fresh-wrater sunfish to seasonal photoperiods and temperatures. Helgoländer weiss. Meeresunters. 9, 459-473.

ROLE of cellular reactions in adaptation of multicellular organisms to environmental temperature, The, 1963. Abstr. in Engl. of the Int. Symp. on Cytoecology. Inst. of Cytology, Acad. of Sci. USSR, Moscow, 86 pp. (Vollst. russ. Ausg. ersch. u. d. Obers. T.: The cell and environmental temperature. Proceedings of the International Symposium on Cytoecology, Leningrad, 31. 5.-5. 6. 1963. Nauka, Moskva 1964, 304 pp. [Übers. i. d. Engl. vorges.] ${ }^{1}$.)

Roots, B. I. \& Prosser, C. L., 1962. Temperature acclimation and the nervous system in fish. J. exp. Biol. 39, 617-629.

Rotн, M., 1964. Adaptation de la thermogenèse à la température ambiante et effect d'économie thermique du groupe chez labeille (Apis mellifica L.). C. R. bebd. Séanc, Acad. Sci., Paris $258,5534-5537$.

SAROJA, K. \& RAO, K. P., 1965. Some aspects of the mechanism of thermal acclimation in the earthworm Lampito mauritii. Z. vergl. Physiol. 50, 35-54.

SCHLIEper, C., 1952. Versuch einer physiologischen Analyse der besonderen Eigenschaften einiger eurythermer Wassertiere. Biol. Zbl. 71, 449-461.

- 1960. Genotypische und phänotypische Temperatur- und Salzgehalts-Adaptation bei marinen Bodenevertebraten der Nord- und Ostsee. Kieler Meeresforsch. 16, 180-185.

- 1966a. Untersuchungen zur ökologischen Zellphysiologie mariner Bodenevertebraten. Zool. Anz. (Suppl. Bd) 29, 239-242.

- 1966b. Genetic and nongenetic cellular resistance adaptation in marine invertebrates. Helgoländer wiss. Meeresunters. 14, 482-502.

- \& KowalsKi, R., 1956. Uber den Einfluß des Mediums auf die thermische und osmotische Resistenz des Kiemengewebes der Miesmuschel, Mytilus edulis L. Kieler Meeresforsch. 16, $37-45$.

SChroeder, C. A., 1963. Induced temperature tolerance of plant tissue in vitro. Nature, Lond. 200, 1301-1302.

ScotT, L. G. \& Strong, D. H., 1964. Effect of sodium alginate on Stapbylococcus aureus during mild heating and freezing. Appl. Micrabiol. 12, 146-149.

Smirh, J. M., 1956. Acclimatization to high temperatures in inbred and outbred Drosophila subobscura. J. Genet. 54, 497-505.

${ }^{1}$ Die anläßlich des Leningrader Symposions über Cytoecology gehaltenen Vorträge sind im Text meist unter der Jahreszahl 1964 zitiert, aber unter ZITIERTE LITERATUR nicht gesondert aufgeführt worden. Es handelt sich um folgende Autoren: Alexandrov, Astaurov, Denko, Feldman et al., Irlina, Lange, Lomagin et al., Losina-Losinsky, Poljansky \& Sukhanova, Precht, Prosser, Rao, Schlachter \& Chernokozheva, Schlieper, Trunova, Tumanov und Ushakov. 
- 1957. Temperature tolerance and acclimatization in Drosophila subobscura. J. exp. Biol. 34, 85-96.

Sroor, W. A., 1955. Loss and gain of heat tolerance by crayfish. Biol. Bull. mar. biol. Lab., Woods Hole 108, 77-87.

Stroganov, N. S., 1940. Physiologische Adaptation und Gasaustausch bei Fischen. Dokl. Akad. Nauk SSR 28, 743-746.

SUMNER, F. B. \& Doudoroff, P., 1938. Some experiments on the temperature acclimatization. and respiratory metabolism in fishes. Biol. Bull. mar. biol. Lab., Woods Hole 74, 403-429.

- \& WeLLS, N. A. 1935. Some relations between respiratory metabolism in fishes and susceptibility of certain anesthetics and lethal agents. Biol. Bull. mar. biol. Lab., Woods Hole 69, 368-378.

THIEDE, W., 1965. Über die hormonale Basis der Adaptation an extreme Temperaturen beim Schwertträger Xiphophorus belleri Hecken (Poeciliidae, Pisces). Z. weiss. Zool. 172, 305-346.

THÖRNER, W., 1920. Untersuchungen über Wärmelähmung und den Erscheinungskomplex der "Gewöhnung" bei der letzteren. Z. allg. Pbysiol. 18, 226-276.

- 1922. Leitungsverlangsamung und Verringerung des Stoffumsatzes als Grundlage der scheinbaren "Gewöhnung" des wärmegelähmt gewesenen Nerven. Pflügers Arch. ges. Physiol. 195, $602-616$.

THORMAR, H., 1962. Effect of temperature on the reproduction rate of Tetrabymena pyriformis. Expl Cell Res. 28, 269-272.

TISCHLER, W., 1965. Agrarökologie. Fischer, Jena, 499 pp.

Tsurudd, H., 1959. Temperature adaptation in fishes. 2. I. Inst. Polytechn. Osaka Cy Univ. (Ser. D) 10, 95-104.

- 1960a. Temperature adaptation in fishes. 3. Biol. J. Nara Women's Univ. (Japan) 10, 11-14.

- 1960b. Temperature adaptation in fishes. 4. J. Inst. Polytechn. Osaka Cy Univ. (Ser. D) 11, 43-54.

- 1960c. Heat and cold tolerance in relation to body size in the guppy Lebistes reticulatus. J. Inst. Polytechn. Osaka Cy Univ. (Ser. D) 11, 55-62.

- \& OHSA WA, W., 1958. The heat and cold temperatures in Lebistes reticulatus as determined by raising and lowering water temperature at constant rates. J. Inst. Polytechn. Osaka $C y$ Univ. (Ser. D) 9, 69-76.

Tumanov, I. I., Kuzina, C. V. \& Karnikova, L. D., 1965. Effect of photoperiods on the frost resistance of apricots and black currant. Fiziologiya Rast. 12, 665-682.

Ullrich, H., 1962. Zur Physiologie der Frostresistenz und Frosthärtung. Angew. Bot. 36, 258-272.

UsHaknov, B., 1964. Thermostability of cells and proteins of poikilotherms and its significance in speciation. Physiol. Rev. 44, 518-560.

VERNBerg, F. J., Schlieper, C. \& Schneider, D. E., 1963. The influence of temperature and salinity on ciliar activity of excised gill tissue of molluses from North Carolina. Comp. Biochem. Physiol. 8, 271-285.

- \& VERNBERG, W. B., 1964. Metabolic adaptation of animals from different latitudes. Helgoländer wiss. Meeresunters. 9, 476-487.

VogeL, W., 1966. Über die Hitze- und Kälteresistenz von Zoothamnium hiketes PREcht (Ciliata, Peritr.). Z. wiss. Zool. 173, 344-378.

WATANABE, Y., 1950. Heating rate and heat-shortening temperature in Eisenia foetida (SAVTGNY). Pbysiol. Zool. 23, 258.

Weatherley, A. H., 1963. Thermal stress and interrenal tissue in the perch Perca fuviatilis (L.). Proc. zool. Soc. Lond. 141, 527-555.

WELLS, N. A., 1935. Change in the rate of respiratory metabolism in a teleost fish induced by acclimatization to high and low temperature. Biol. Bull. mar. biol. Lab., Woods Hole 69, 361-367.

- 1935. Variations in the respiratory metabolism of the Pacific killifish, Fundulus parvipinnes, due to size, season, and continued constant temperature. Physiol. Zool. 8, 318-336. 
Whitford, W. G. \& Hutchison, V. H., 1965. Effect of photoperiod on pulmonary and cutaneous respiration in the spotted salamander, Ambystoma maculatum. Copeia 1965, $53-58$.

WIESER, W., 1965. Die Steuerung von Stoffwechselvorgängen bei Porcellio scaber Latr. durch Temperatur und Licht. Zool. Anz. (Suppl. Bd) 28, 359-364.

YAMADA, S., 1924. Uber die Wirkung höherer Temperaturen auf sympathische Kaltbluternerven. Pfligers Arch. ges. Pbysiol. 202, 73-87.

YARWOOD, C. E., 1964. Thermophylaxis in bean rust. Nature, Lond. 203, 426-427.

- 1965. Temperature and plant disease. Wld Rev. Pest Control 4, 53-63.

ZERBST, E., 1964. Ein Analogrechenverfahren zur Analyse biologischer Anpassungsvorgänge mit der Methode der Thermodynamik irreversibler Prozesse. Helgoländer wiss. Meeresunters. 9, 380-391.

- 1966. Zur Auswertung biologischer Anpassungsvorgänge mit Hilfe der Fließgleichgewichtstheorie. Untersuchungen zur Temperaturanpassung der Frequenzbildung isolierter Froschund Rattenherzen. Berlin, Nat.-math. Hab.-Schr. 